\title{
Fatsa/Cıngırt Kayası 2012-2014 Sezonu Kazılarından Ele Geçen Unguentariumlar
}

\author{
Doç. Dr. Ayşe Fatma Erol \\ Gazi Üniversitesi Edebiyat Fakültesi \\ Arkeoloji Bölümü \\ aferol@gazi.edu.tr
}

\author{
Deniz Tamer \\ Gazi Üniversitesi Sosyal Bilimler Enstitüsü \\ Arkeoloji ABD Doktora Öğrencisi \\ astyanaks9@yahoo.com
}

Öz

Cıngırt Kayası Doğu Karadeniz Bölgesi'nde Ordu/Fatsa İlçesi Yapraklı Köyü sınırları içinde bulunan konumuyla, Antik Çağda Pontos olarak adlandırılan bölgede yer almaktadır. Antik kaynaklarda VI. Mithradates Dönemi'nde Doğu Karadeniz Bölgesi'nin kontrolü ve savunma stratejisi kapsamında oluşturulan Phrourionların varlığından söz edilmektedir. Ağırlıklı olarak yerleşimin zirve kesiminde yürütülen kazı çalışmalarından elde edilen verilere dayanarak Cingırt Kayası'nın VI. Mithradates Dönemi'nin Phrourion karakterli yerleşimlerinden birisi olabileceği önerilmektedir. Makalenin konusunu oluşturan materyal, 2012-2014 yılları arasında devam eden kazılarda yerleşimin zirve kesiminde yürütülen çalışmalardan ele geçen unguentarium parçaları arasından seçilmiş profil veren örneklerdir. Çalışma kapsamına alınan örnekler, kazı verileri ve paralel materyal ışı̆̆ında tipolojik ve kronolojik açıdan değerlendirilerek, katalog ve levha bilgileriyle sunulmaktadır. Doğu Karadeniz Bölgesi'nde az sayıda yürütülen kazı çalışmalarından birisi olan Cıngırt Kayası'ndan ele geçen söz konusu materyalin tanıtılması ve değerlendirilmesiyle; konuyla ilgili ilk bilimsel verilerin paylaşılması ve bölge arkeolojisine katkı sağlanması amaçlanmıştır.

Anahtar Kelimeler: Cingırt Kayası, Doğu Karadeniz, Hellenistik Dönem, Unguentarium. 


\title{
Unguentariums Obtained from Fatsa Cıngırt Kayası During 2012-2014 Excavations
}

\begin{abstract}
Cingırt Kayası is located in a region called "Pontos" in ancient times, which is currently within the borders of Yapraklı village, in the town of Fatsa, city of Ordu in the Eastern Black Sea Region. Sources from the Antiquity talk about Phrourion that were built to control and defend the Eastern Black Sea Region during the reign of Mithradates VI. Based on the excavations conducted predominantly on the summit of Cingırt Kayas1, it is suggested that Cingırt Kayası was part of a security chain that consisted of Phrourion to provide control and defense of the Pontic Region during the reign of Mithradates VI. The material that constitutes the subject of study was discovered from excavations carried out at the top of the settlement during the ongoing excavations between the years 2012-2014. They are presented with their catalogue and plate information, through the evaluation of their typology and chronology based on data from the excavations and comparisons with similar materials. There have been few excavations conducted in the Eastern Black Sea Region, and thus this study aims to share one of the first findings of the unguentariums obtained from Cingirt Kayasi excavations and to contribute to the studies related to the unguentariums through the Black Sea Basin.
\end{abstract}

Keywords: Cingırt Kayası, Eastern Black Sea Region, Hellenistic Period, Unguentarium. 


\section{GíRiş}

Antik Dönemde Pontos Bölgesi'nde ${ }^{1}$ (Res. 1, 2), günümüzde ise Doğu Karadeniz Bölgesi coğrafi sınırları içerisinde yer alan Cıngırt Kayası², Samsun-Ordu karayolu üzerinde, Fatsa ilçe merkezine 5km. mesafede, Yapraklı Köyü sınırları içinde, $200 \mathrm{~m}$. rakımlı bir tepe üzerinde, denize ve vadiye hakim bir konumda yer almaktadır (Res. 3). 2012- 2014 yılları arasında devam eden kazı çalışmaları Cıngırt Kayası'nın zirve kesiminde (Res. 4) ve kuzey yamaçta yürütülmüştür. Kazılan alanlardan elde edilen arkeolojik bulgularla son Pontos Kralı VI. Mithradates (MÖ 120-63) Dönemi'nde phrourion işlevinde olduğu önerilen yerleşimin ${ }^{3}$, Roma ve Bizans Dönemlerinde de iskana açık olduğu arkeolojik verilerle anlaşılmıştır (Erol 2013: 183-196; Erol, 2014: 383-400; Erol-Tamer 2014: 73-85; Erol, 2015: 453461).

Çalışmanın konusunu oluşturan materyal, 2012-2014 kazı sezonlarında yerleşimin zirve kesiminde yürütülen çalışmalardan ele geçen unguentarium parçaları arasından seçilmiş profil veren örneklerdir. Cıngırt Kayası unguentariumlarının tanıtım ve değerlendirilmesinden önce, bu kapların köken, fonksiyon, form gelişimleri ve yayılım alanlarıyla ilgili bilgiler aşağıda sunulmaktadır.

\section{Etimoloji ve Fonksiyon}

Unguentariumların ${ }^{4}$, mezar hediyesi olarak ölü yakınlarının gözyaşlarını içine biriktirdikleri gözyaşı şişeleri oldukları belirtilmekle birlikte, bu kapların söz konusu amaca hizmet etmedikleri ve antik dönemdeki adlandırmalarının da unguentarium olmadığ 1 ortaya konulmuştur (Thompson 1934: 473; Hellström 1965: 23). Bu adlandırma, 20. yüzyıl başlarında Kartaca'da kazı yapan Fransız arkeologlar tarafından verilmiştir (Gaucker 1915, 514). Antik Dönemde bu formla ilgili net bir adlandırma bulunmamakta olup (AndersonStojanović 1987: 106; Laflı 2003: 17), farklı çalışmalarda lacrimaria ya da lacrimatorium

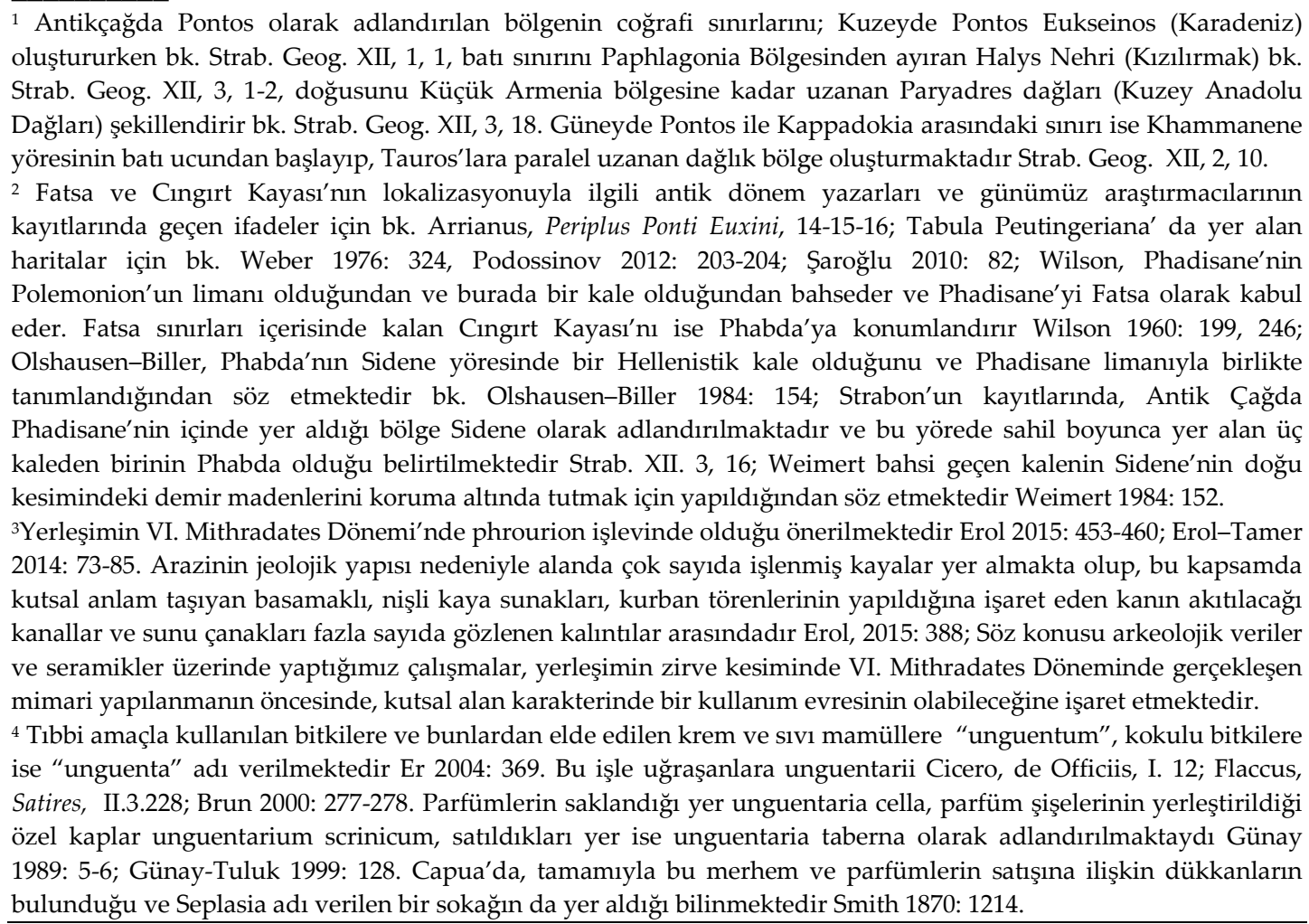

SEFAD, 2018 (39): 267-292 
(Thompson 1934: 472), balsamaria (Hellström 1965: 23) ve olfactoriolum (Anderson-Stojanović 1987: 106 dn. 7) olarak geçmektedir. Plinius, vasa unguentaria'dan bahsetmektedir ${ }^{5}$.

Unguentariumların sadece çeşitli parfüm ${ }^{6}$ ve değerli yağların ${ }^{7}$ saklanması fonksiyonunda olmadığı, aynı zamanda kozmetik ürünler (Anderson-Stojanović 1987: 116. dn. 65), sakız (Hellström 1965: 24. dn. 1.) sivı baharatlar, bal, sirke (Gürler 1994: 63, dn. 4; Günay 1989: 3), şarap (Barag 1972: 24-26), reçine şarabı (Alcock 1980: 62), zeytinyağı (Rotroff 1997: 175, dn. 28), kırmızı aşı boyası (Anderson-Stojanović 1987: 116), ilaç8 ve bitkisel yağların da (Greenewalt ve diğ. 1983: 182, 183) söz konusu formun içinde muhafaza edildiği analizler sonucu tespit edilmiştir. Dolayısıyla unguentariumlar kozmetik amaçlı renklendirici tozlardan, kurutulmuş bitkilere, merhem ve ilaçlardan çeşitli yağlara kadar birçok maddenin muhafazasında kullanılmıştır (Stern 2001: 43; Anderson-Stojanović 1987: 115, 116).

Unguentariumlar Hellenistik ve Roma Dönemi nekropollerinde mezar hediyesi olarak $^{9}$ ve libasyon amaçlı kullanımlarının (Dusenbery 1998: 798; Kahane 1952: 131-132; Kurtz-Boardman 1971: 144) yanı sıra kutsal alanlara sunu amacıyla da bırakılmışlardır ${ }^{10}$. Ayrıca az sayıda evlerin ambarlarında da bulunmuşlardır ${ }^{11}$. Kadınlara ait mezar stellerindeki tasvirlerde unguentariumların yanında pyksis ve aynaların da bulunması, bu formun kadınlar tarafından kullanılan kozmetik amaçlı günlük kullanıma yönelik kaplar olduğunu da göstermektedir (Civelek 2012: 77-90).

Unguentariumların yıkanma ve antik dönem sportif yarışmalarıyla da bağlantısı bulunmaktadır (Smith 1870: 1214). Platus ve Cicero'nun kayıtlarında geçen Ampulla ve ampulla et strigilis, palaestradaki kullanımlarıyla ilişkilidir (Plautus, Persia, 123ff; Cicero, De finibus bonorum et malorum, IV. 30).

\footnotetext{
${ }^{5}$ Plinius, Naturalis Historia, XXXVI, 12; Hellström'e göre, antik dönemdeki bu adlandırmalar yalnızca içindeki malzemeyi değil, formu da tanımlamaya yöneliktir ve Plinius büyük olasıllkla kendi döneminin alabaster kaplarından söz etmektedir Hellström 1965: 24-25. Anderson-Stojanović 'e göre alabastron ve lekythos terimlerinin her ikisi de, antik dönemde bu küçük şişeler için kullanılmış olabilir, ancak unguentariuma açı bir şekilde referans olacak kaynak literatürde bulunmamaktadır Anderson-Stojanović 1987: 106.

6 Thompson 1934: 473; Rotroff 1997: 137-138; Antik Dönemde Kyzikos, Tarsus, Phaselis, Mende, Delos, Rhodos, Kos, Korinth, Atina, Capua ve Naples gibi birçok yerin parfüm ve benzeri sıvı ürettiği bilinmektedir Plinius, Nat. Hist., XII. 2. Antik Dönemde parfüm imal eden yerler için bk. Rotroff 1997: 176, dipnot. 31.

7 Thompson 1934: 335; Hayes 1997: 85; Spicatum, iasminum, crocus, megalesium, rosaceum, susinum-lilinumliliaceum, cyprinum, amaracinum, metopium, mendesium, nardinum, vücut ve bazen saçta kullanılan çok çeşitli ve pahalı yağlardan bazılarıdır Dioscorides, De Materia Medica, I-25, 39, 53,62, 65, 68, 71,72, 75.

${ }^{8}$ Aydıngün 2014: 38. Bathonea Antik kentinde yapılan kazılardan ele geçen unguanteriumların içinde koruna gelmiş kalıntılardan alınan analiz örnekleri, çevredeki endemik bitkilerden elde edilen Methanone ve Phenanthrene olarak bilinen depresyona ve kalp rahatsızlı̆ına iyi gelen iki ilacın özüne ait olduğu, TÜBİTAK (Gebze) tarafından yapılan analiz çalışmasıyla tespit edilmiştir (Hürriyet Web, 16 Ekim 2016) .

9 Saraçoğlu 2011: 3; Makedonya, Yunanistan, Kıbrıs, Samos, Sırbistan-Hırvatistan, Bulgaristan, Rusya, Anadolu, Filistin, İtalya, İspanya' da mezarlardan ele geçen unguentarium buluntuları için bk. Anderson-Stojanović 1987: 105106 dn. 2; Atina'da Pandrosou Caddesi'nde mezar buluntusu olarak ele geçen bir unguentariumun içinden obol çıkması, bu kapların mezar sahibi ve Hades-Styx-Charon inancına hizmet eden kullanımlarının da olduğuna işaret etmektedir Åström 1967: 189.

10 Rotroff 1997: 176; Thompson 1934: 472; Aegina Apollon kutsal alanı adak eşyaları arasındaki örnekler için bk. Scherrer 1982, 88; Pergamon Kapıkaya' da Kybele kültü adak eşyaları için bk. Nohlen-Radt 1978: 83; Lagina Hekate tapınağının naos ve temenosundan ele geçen unguentariumlar için bk. Tırpan-Söğüt 2001: 301, 309, Res. 10; Nekropol alanlarından ele geçen unguentariumlar ölü kültü ile ilişkilendirilirken, kutsal alanlardan ele geçenler adak eşyaları kapsamında değerlendirilmektedir Korkut-Işın 2015: 214.

11 Thompson 1934: 472; Mezar dışı kontekslerden ele geçen unguentarium buluntuları için bk. Anderson-Stojanović 1987: 106. dn. 3.
} 


\section{Orijin}

İlk örnekleri Erken Hellenistik Dönem'de ortaya çıkan unguentariumların (Kotitsa 1998: 153, 154; Rotroff 2006: 15), MÖ 4. yüzyıl ile MS 7. yüzyıl arasında, Filistin'den İspanya'ya kadar tüm Akdeniz havzasında yaygın kullanımda oldukları bilinmektedir (Thompson: 1934, 472-474; Hellström 1965: 23; Khairy 1980: 85-91; Rotroff 1984: 258; Forti 1962: 143-155, Anderson-Stojanović 1987: 106). Söz konusu kapların hangi formdan geliştiği net bilinmemekle birlikte, Klasik Dönem'de tüm Akdeniz dünyasında mezar armağanı olarak yaygın kullanılan lekythosların yerini, Hellenistik Dönem'de unguentariumların aldığ1 öngörülmektedir (Thompson 1934: 335; Anderson-Stojanović 1987: 106; Hellström 1965: 25; Jones 1950: 171; Vaag ve diğ. 2002: 41; Heimberg 1982: 26; Dusenbery 1998: 798; Khairy 1980: 85; Berlin 1997: 58; Pemberton 1985: 284; Rotroff 2006: 138; Kurtz-Boardman 1971: 164). MÖ 4. yüzyıl sonlarına kadar kullanılan lekythoslarla benzer işleve sahip unguentariumların erken örnekleri arasında (Hellström 1965: 25; Oakley 2004: 4; AndersonStojanović 1987: 106); geniş ve kısa kaide, dışa çekik ağız, kaideden genişleyerek yükselen ve omuzlarda keskin bir hatla boyuna doğru daralan gövde profili gibi form özelliği benzerlikleri, bu iki form arasında bir devamlılık olduğunu düşündürmektedir ${ }^{12}$.

$\mathrm{Bu}$ formun ortak kökeniyle ilgili olarak bilim insanlarının farklı görüşleri bulunmaktadır ${ }^{13}$. Hellström ve Anderson-Stojanović ise Akdeniz'deki erken dönem unguentariumlarının form olarak çok fazla çeşitlilik gösterdiğini, bu nedenle hepsi için ortak bir köken önermenin yerine, birden çok yerin düşünülmesi gerektiği görüşündedirler (Hellström 1965: 26; Anderson-Stojanović 1987: 105). Jones ise, taşıyıcı kaplar olan unguentariumların, parfüm imal edilen yerlerin yakınında üretilmiş olabileceğini önermektedir ${ }^{14}$.

\section{Malzeme, Form Gelișimi ve Yayılım Alanı}

Unguentariumlar farklı malzemelerle üretilmiş olmakla birlikte, maliyetinin ucuz olması nedeniyle pişmiş topraktan üretimi daha yaygındır (Laflı 2003: 155). Pişmiş toprak unguentariumlar cam üfleme teknolojisinin yaygınlaşmadığı dönemlerde daha yaygın kullanımda iken, Roma İmparatorluk Dönemi başlangıcından itibaren artık tüm mezarlarda cam unguentarium örneklerine rastlanılmıştır (Erten-Yağcı 1993: 132-152). Unguentariumun üretim kalitesi, kullanım amacına göre değişmektedir. Ticari amaçla üretilenler nitelikli, temiz kilden ve astarlı örneklerden, mezar alanlarında kullanılanlar ise kalitesiz kilden, son derece özensiz üretilmiş örneklerden oluşmaktadır ${ }^{15}$. Pişmiş toprak malzemenin geçirgenlik

\footnotetext{
12 Unguentariumların Hellenistik Dönem öncesi prototipi olarak, morfolojik özelliklerinin benzemesi ve Klasik Dönem mezarlarında yoğun bulunmasından dolayı lekythos önerilmiş olmakla birlikte, son yapılan morfolojik araştırmalar bu kap formunun lekythos dışında, amphoriskos, alabastron ve lydion gibi kökenleri daha erkene dayanan formlardan türediği ve bu formlardan gelişen unguentariumların lekythoid, fusiform ve priform olmak üzere üç ayrı tip oluşturduğu ileri sürülmüştür Camilli 1999: 24-37; Dotterweich 1999: 4; Laflı 2003: 156.

${ }_{13}$ Konuyla ilgili farklı görüşler için bk. Thompson 1934: 472-474; Lapp 1961: 228; Vessberg-Westholm 1956: 73; Sparkes-Talcott 1970: 191-192; Guz-Zilberstein 1995: 304; Aström 1964: 189; Dusenbery 1998: 799; Forti 1962 : 146.

14 Jones 1950: 171; Anderson-Stojanović parfüm üretimiyle bağlantılı olarak çok sayıda unguentarium üreten küçük atölyelerin bulunduğunun düşünülmesi gerektiğini belirtmiş ve bu kapların boyunlarının kırılma tehlikesi nedeniyle, kullanılacak içeriğin büyük kaplarla gönderilip, sonrasında dolum işleminin yapılmasının daha olası olduğu görüşündedir Anderson-Stojanović 1987: 115.

15 Anderson-Stojanović 1987: 117, 120; Stobi'de mezar buluntusu olarak ele geçen özensiz yapılmış iki unguentariumun boyun kısımlarının kille kaplı olması, bu tür örneklerin içerisine herhangi bir madde doldurmak yerine, sembolik kullanıma yönelik mezar armağanı olarak seri üretim yapıldıklarını düşündürmektedir AndersonStojanović 1987: 121, 122. Bununla birlikte mezarlardan gelen kaliteli unguentariumlar için, bazılarının üzerindeki aşınma ve kullanım izleri göz önüne alınarak, ölen kişinin sağlığında kullandığı unguateriumların birlikte gömülebileceği olasılığını da akla getirmektedir Anderson-Stojanović 1987: 118, 119.
}

SEFAD, 2018 (39): 267-292 
özelliğinden dolayı16, değerli parfümlerin taşınmasında farklı malzemelerin kullanılmış olabileceği önerilmektedir (Hellström 1965: 24).

Kullanım alanları Hellenistik ve Roma Dönemlerinde değişmeyen unguentariumların formları Hellenistik Dönem'de iğ, Roma Döneminde torba formunu almıştır ${ }^{17}$. Geç RomaErken Bizans Dönemi'nden itibaren ortaya çıkmaya başlayan Geç Antik Çağ unguentariumları; kaidesiz, uzun ince gövdeye ve çok uzun olmayan boyun ile geniş olmayan bir ağıza sahiptir (Hayes 1971: 243-248) ve Hıristiyanlığın getirmiş olduğu ayinler çerçevesinde kullanım alanları şekillenmiştirir ${ }^{18}$.

Erken örneklerde geniş kaideli olmaları nedeniyle dik durabilen, ancak formun uzamasıyla birlikte bu özelliklerini yitiren iğ formlu unguentariumların ${ }^{19}$ alabastron, aryballos ve amphoriskoslarda olduğu gibi (Sparkes-Talcott 1970: 43, 156, 80) bir destek aracılığıyla kullanımları düşünülmekle birlikte, bu amaç için kullanılmış ayakların ele geçmemesi (Khairy 1980: 85; Anderson-Stojanović 1987: 114), boyunlarından bir iple asılarak kullanıldıkları (Dusenbery 1998: 799; Anderson-Stojanović 1987: 114) ya da yatay olarak kullanıldığını akla getirmektedir ${ }^{20}$. Form özelliği olarak kapalı ve dar boyunlu olmaları, içindeki maddelerin özelliğine göre bir kaşık yardımıyla alınabileceği ya da boyunlarının kırılması suretiyle kullanılabileceklerini de düşündürmektedir (Anderson-Stojanović 1987: 115 dn. 61, 120 dn. 97).

Hellenistik ve Erken Roma Dönemleri'nde Akdeniz coğrafyasında tüm nekropollerde görülen unguentariumların (Anderson-Stojanović 1992: 81), Karadeniz Bölgesi örnekleri Tomis (Bucovala 1967: 56, 36/c; 60, 38/c-e; 64, 40/b; 65, 41/e,f; 81, 49/c; 84, 51/a; 87, 53/a; 91, 57/a; 94, 59/e, 122, 78/a-f; 126, 86/a,b), Apollonia Pontica (Hermary ve diğ. 2010: Pl. 116/a-e; Ivanov 1963: 245-252, fig. 97, Pl. 127, 704), Albeşti (Buzoranu-Barbulescu 2008: Pl. XL, LXXIII), Olbia (Lomtadze-Zuravlev 2014: 187, Fig. 8/9; Bouzek 1990: 63, Fig. 17/1-10; Parovich-Peshikan 1974: 108-113; Ivchenko 2015: 271 Pic. 9/3,4; Karjaka 2010 (a): Pl. 220/G 134-140, Karjaka 2010 (b): Pl. 251/191, 192; Handberg-Petersen 2010: Pl. 145/ Da-623, 624, 627, Dc-629, 630), Scythian Neapolis (Zajcev 2005: 269, Fig. 4/1-13; 272, Fig. 7/29-32, 34, 35), Nogajcik (Mordvinceva 2005: 278 Fig. 3/2), Panskoye (Kasaev 2002: Pl. 91, Fig. C 97-101), Chersonesos (Belov ve diğ. 1953: 114; Kaposina 1959: 137, Fig. 39), Amisos (Ünan 2010: 661-

${ }_{16}$ İçinde bulunan sıvının sızmasının önlenmesi amacıyla, ticari unguentariumların iç yüzeyinin balmumu ya da don yağı ile kaplanarak işlemlerden geçirildiği düşünülmektedir Anderson-Stojanović 1987: 116; Rotroff 1997: 176 dn. 31.

${ }_{17}$ Dotterweich 1999: 1-15; Roma Dönemi torba formlu unguentariumların erken örneklerinin, cam tekniğinin ortaya çıktı̆̆ı MÖ 1. yy'ın ortalarında görülmeleri, küçük boyutlu olmaları ve form olarak cam örneklere benzemeleri nedeniyle, camlardan etkilenerek üretildikleri yorumunu getirmiştir Harden 1969: 47.

18 Türker 2005: 311-328; Hellenistik ve Erken Roma Dönemleri'nde yoğunlukla nekropol alanlarında bulunan unguentariumlar, Hıristiyanlıkla birlikte dinsel-liturjik fonksiyonlar kazanmıştır bk. Anderson-Stojanović 1987: 105 vd.; Hayes, bu tipteki unguentariumların kutsal topraklardaki kaynaklardan elde edilen suyun ve yağın taşınması amacıyla doğuda üretildiğini ileri sürmüş ve Filistin'i üretim merkezi olarak göstermiştir Hayes 1971: 246; Ancak Geç Antik Çağ unguentariumlarının Anadolu'da birçok merkezde yoğun olarak ortaya çıkması, bu görüşü geçersiz kılmıştır Atik 1999: 247; Özüdoğru-Dündar 2007: 150-151; Özhanlı-Şen 2007: 145, 146; Şimşek-Duman 2007: 295; Dündar 2008: 33-37.

19 Anderson-Stojanović 1987: 114; Bununla birlikte, mezar stellerinde betimlenen iğ formlu unguentariumların, raflarda hiç bir destek olmadan ayaklarının üzerinde durduğuna da dikkat çekilmektedir Pfuhl-Möbius 1977: nos. $384,507,538,892,909,924,989,922$.

${ }^{20}$ Geç Roma unguentarium örneklerinde kullanılan tıpalar için bk. Türker 2005: 313; Fırat 2003: 91-95. Söz konusu tıpalı örnekler üzerinden, iğ formlu unguentariumlarda da benzer kullanımın olabileceği düşünülmüş, ancak söz konusu örneklere uygun tıpaların ele geçmemesi, malzemenin balmumu ve mantar gibi organik maddelerden üretildiği önerisinin yapılmasına neden olmuştur Anderson-Stojanović 1987: 114. Ayrıca Geç Antik Çă̆ unguentariumlarında sızdırmazlığın sağlanmasına yönelik pişmiş toprak tıpaların üzerine ahşap tıkaçların kullanıldığı in situ tespit edilmiştir Şimşek-Duman 2007: 289, Res. 8, 18. 
663; Akkaya 1993: 216, Fig. 14) ve Ordu Kurul Kalesi'nden (Şenyurt-Akçay 2016: 244, Lev. 9/1) ele geçmiştir ${ }^{21}$.

\section{Cıngırt Kayası Örnekleri}

Cıngırt Kayası kazıları 2012-2014 yılları arasında yürütülmüş ve kazı çalışmaları sırasında ele geçen unguentarium parçaları arasından profil veren örnekler seçilerek, bu çalışmada değerlendirilmiştir ${ }^{22}$. Unguentariumların çoğunluğu zirve kesiminde yürütülen kazı çalışmalarından ele geçmiş olup, bu çalışmada tanitılan örneklerin çoğunluğunun, katalogda belirtildiği gibi K 16 açması güneydoğu sektöründen (bkz. Res.4), Geç Hellenistik Dönem malzemesinin yoğun geldiği tabakalardan ele geçtiği görülmüştür. Basamaklı Tünel yapısının kuzeyinde oluşturulan mimari düzenleme, duvar temellerinden anlaşılacağı üzere, yan yana dizilmiş kare mekanlardan oluşmaktadır (bkz. Res.4). K16 KD sektörünün içerisinde yeraldığı kare formlu bir alan oluşturan mekandan 1 adet, L16 GB sektörünün içerisinde yeraldığı yine kare formlu mekandan 1 adet, bu mekanla bağlantılı ve onun batısında yer alan K16 GD ve K17 KD sektörlerinin oluşturduğu dikdörtgen formlu mekandan 5 adet, K15 GD sektörünün içerisinde yer alan, kazısı tamamlanmadığı için net konuşamadığımız, ancak sözü edilen diğer sektörlerde olduğu gibi kare formlu bir mekan oluşabileceği öngörüsünde bulunduğumuz sektörden de 1 adet olmak üzere toplam 8 adet domestik kullanıma hizmet eden unguentarium ele geçmiştir. Basamaklı Tünel yapısının güneyinde ise mimari düzenleme daha farklıdır. Burada toprağa gömülü halde çok sayıda pithosların da yer aldığı depolama ve işlik alanı mevcut olup, söz konusu kesimden ele geçen bir adet unguentariumun bu üretim sürecine hizmet ettiği düşünülmektedir ${ }^{23}$. Mezar buluntusu olarak ise, zirvenin doğu yamacına doğru uzanan P 20 açmasının güneydoğu sektöründe yer alan ana kayaya oygu khamasorion lahit mezarın tabanından ele geçen bir örnek bulunmaktadır (Erol-Tamer 2014: 93, Fig. 27; Erol, 2015: 453, fig. 8.5) (bkz. Res. 4).

$\mathrm{Bu}$ çalışmada katalog ve levha bilgileriyle tanıtılan Cingırt Kayası unguentariumları tipolojik olarak üç ayrı grup oluşturmaktadır; Bunlardan birinci grubu sekiz örnekle iğ formlu unguentariumlar, ikinci grubu bir örnekle kubbe form ağız kenarlı unguentarium, üçüncü grubu ise yine bir örnekle küresel gövdeli unguentarium oluşturmaktadır. Söz konusu materyalin tarihlendirilmesinde paralel malzeme ve kazılar sırasında birlikte ele geçen diğer arkeolojik buluntulardan faydalanılmıştır.

Katalog bilgileri ile birlikte verilen Cingırt Kayası unguentariumlarının hamur ${ }^{24}$ özellikleri farklılıklar göstermektedir. Hamur içerisinde kum, mika, kireç ve şamot katkıları görülmekle birlikte, katkı oranlarının farklı olduğu gözlenmektedir. Söz konusu örnekler tipolojilerine göre gruplandırılarak ayrı başlıklar altında aşağıda sunulmaktadır.

\footnotetext{
${ }^{21}$ Güney Karadeniz sahil bölgesinde yer alan Herakleia Pontike, Sinope, Trapezus gibi büyük kentlerin nekropol alanlarının modern yerleşimin altında kalması, unguentariumlar gibi çoğunluğu mezar buluntusu olan malzemelere örnek gösterilmesinde sıkıntı oluşturmaktadır.

${ }^{22}$ Cıngırt Kayası kazılarından ele geçen unguentarium örnekleri, öncül yayınlarımızda yerleşim kronolojisini destekleyen örnekler bazında tanitılmıştır bk. Erol 2014: 396, resim 9; Erol-Tamer, 2014: 83, fig. 24/1-3; Erol, 2015 : 453, fig. 8.4-5; Söz konusu materyalin de yer aldığı Cıngırt Kayası seramikleri Doktora tezi kapsamında Deniz Tamer tarafından çalışılmaktadır.

${ }^{23}$ Söz konusu işliğe ait detaylı bilgi 2014 yılında Prof. Jan Bouzek onuruna Prag'da düzenlenen konferans için hazırlanan anı kitabı içerisinde "The Place Of Cıngırt Kayasi in the Pontic Region During The Reign Of Mithradates VI" başlıkıı makalede yer almaktadır. Söz konusu anı kitabı yayım aşamasındadır.

${ }^{24}$ Hamur ve astar renklerini belirlemede Munsell soil color charts. Revised washable edition: GretagMacbeth, New York, 1992 kullanılmıştır.
}

SEFAD, 2018 (39): 267-292 


\section{1. İğ Formlu Unguentariumlar}

MÖ 4. yüzyıldan, MÖ 1. yüzyıla kadar görülen ĭ̆ formlu unguentariumlar en uzun süre kullanımda kalan unguentarium formudur (Anderson-Stojanovic 1987: 108-110; Tavukçu 2006: 88; Dündar 2008: 3; Fırat 2012: 296; Baldıran 2015: 71; Yıldız 2016: 7). İğ gövde biçiminin, unguentariumların en erken örneklerini oluşturan gövdesi küre biçimli ve dar kaideli, yuvarlak karınlı unguentariumlardan geliştiği öngörülmektedir (AndersonStajanovic 1987: 108-110; Körsulu 2011: 72; Baldıran 2015: 73). MÖ 4. yüzyılda ortaya çıkan ${ }^{25}$ küçük boyutlu minyatür örneklerden (Rotroff 2006: Fig. 63/434) büyük boyutlulara (Wiseman- Mono-Zissi 1976: 280, fig.11; Dotterweich 1999: 6; Dündar 2008: 112, 158, Lev. 9. U83) ve bazen de kulplu örneklere (Forti 1962: 151; Grozdanova 1990: 66-73, Lev. 35, no. b; Drougou 1991: 103, 116; Stajanovic 1987: 108, dn. 16; Tzanavari 2010: 463, Res. 7; Peshikan 1974: 109, Fig. 93. 1, 2; Dündar 2008: 101, 147, Lev. 3. U30; Buzoianu-Bărbulescu 2008: Pl. XL. C99, LXXIII. C99; Korkut-Işın 2015: 226, Res 1. 2) kadar çeşitlilik gösteren, oldukça uzun bir kullanım evresine sahip olan iğ formlu tip, Hellenistik Dönem boyunca farklı gövde profillerine sahip olmuştur (Rotroff 2006: 153-154). MÖ 4. yy sonu, 3. yy başına tarihlenen erken dönem örnekleri; dışa çekik ağız profili, kısa ve ince boyun, geniş omuz, şişkin karın ve henüz oluşmaya başlayan ayak kısmı ile dikkat çekmektedir (Dündar 2008: 13, 57 Tablo 2 (Tip 2A).

Zamanla formda uzama olmuş (Dotterweich 1999: 1-15) ve erken örneklerden farkl1 olarak ayak bölümü oluşarak, gövde ortasında bulunan şişkinliğin azalmasıyla tam olarak "iğ" biçimine dönüşmüştür (Anderson-Stajanovic 1987: 108-109; Dündar 2008: 57-58, Tablo 2; Yaşar 2010: 8). Formun genel gelişiminde, boyun ve ayak uzunlukları Hellenistik Dönem içinde farklılıkları ortaya koymakta ve tarihlemede bir kriter olarak kullanılmaktadır (Anderson-Stojanovic 1987: 106-109). Bununla birlikte Hellenistik Dönem iğ biçimli unguentariumları için form gelişimi üzerinden standart bir kronoloji oluşturmanın zorluğu belirtilmektedir'26.

Cıngırt Kayası'ndan ele geçen iğ biçimli unguentariumlar form özellikleri dikkate alındığında kendi içinde kronolojiye bağlı olarak ufak nüanslar bulunan 4 ayrı alt grup oluşturmaktadır. Bunlar hamur ve astar özellikleri bakımından da birbirinden farklılıklar göstermektedir.

1.1. Birinci grubu kahverengi hamurlu ve gri astarlı Kat. No. 1 (Lev. 1/1) ve 2 ' de (Lev. 1/2) gösterilen örnekler oluşturmaktadır.

Hamur ve astar yönünden birbirine yakın olan söz konusu örneklerden Kat No. 1'de gösterilen örneğin ayak kısmı Kat. No. 2'ye göre biraz daha kalın ve kısa olup, astarı daha canlı ve koyu renklidir. Her iki örnek eksenin merkezden kayması ile oluşan bir eğriliğe, dolayısıyla özensiz bir işçiliğe sahiptir.

Kat. No.2'de gösterilen örneğin ayaktan gövdeye geçişi iki adet yivle vurgulanmıştır. Her iki örnek bir kaideye oturan içi dolu ve nispeten kalın ayak kısmı ile MÖ 2. yüzyılın ortalarına ait form özellikleri göstermekte olup (Bucovala 1967: 84, Fig. 51/a - 123, Fig. 78/c;

\footnotetext{
${ }^{25}$ Doğu Akdeniz'de MÖ. 4. yy'dan öncesine ait bir örnek bulunmamakla birlikte, İspanya Ampurias'dan ele geçen MÖ 5. yüzyılın ortalarına ait örnekler, unguentariumların Batı Akdeniz'deki daha erken varlı̆̆ı için kanıtlar oluşturmaktadır Forti 1962: 146.

${ }^{26}$ Unguentariumlarda kalın ve kısadan, ince ve uzuna doğru bir form gelişimi görülmekle birlikte, i $\breve{g}$ formlu unguentariumların farklı formlarının ayn zaman diliminde kullanıldığı ve ayrıca erken örneklerin geç dönemde kullanımının olduğu Ampurias, Samos ve Makedonya'dan aynı konteksten birlikte ele geçen örneklerden bilinmektedir bk. Anderson-Stajanovic 1987: 109.
} 
Zuravlev ve diğ. 1997: 419, Abb. 7/6), kötü fırınlanmış olmaları ve özensiz işçilikleriyle dikkat çekmektedir.

1.2. İkinci grubu oluşturan Kat. No. 3 (Lev. 1/3) ve $4^{\prime}$ te (Lev. 1/4) gösterilen iki ayakkaide parçası ile Kat. No. 5 (Lev. 1/5) ve 6'da (Lev. 1/6) gösterilen parçaların hamur ve astarları kırmızının açı ve koyu tonlarına sahiptir. Örneklerde astar uygulaması Kat. No. 6 haricinde küçük parçalar halinde korunmuştur.

Kat. No. 3'teki parçanın korunan kısımlarından kaide tabanında görülen belirgin konkavlık, içi dolu ayağın kalınlığı ve gövdeye doğru hafif genişleyerek açılması MÖ 2. yüzyılın ikinci yarısında görülen form özellikleridir (Anderson-Stojanović 1992: Pl. 67/564, $565)$.

Kat. No. 4, 5 ve 6'da gösterilen örnekler, Kat. No. 3'ten farklı olarak yivle profillendirilmiş bir kaideye sahiptir.

Kat. No. 4'de yer alan unguentariumun ayağı içi dolu ve nispeten kalındır. Kalın ayak kısmı yivli bir kaideyle son bulmaktadır. Kaide tabanında görülen konkavlık Kat. No. 3'teki örnek kadar belirgin değildir. Bu özellikleri ile Kat. No. 4'te gösterilen örnek, kaide tabanında görülen belirgin konkavlığa sahip Kat. No. 3 ile, yine kalın ayak kısmı yivli bir kaideyle son bulan ancak kaide tabanında konkavlık oluşturmayarak düz bir tabana sahip olan Kat. No. 5 ve Kat. No. 6 arasındaki geçiş formudur. Form bu özellikleriyle MÖ 2. yüzyılın son çeyreğine tarihlenmektedir (Lomtadze-Zuravlev 2014: 187, Fig. 8/9).

Kat. No. 5'de gösterilen örnek, Kat. No. 3 ve Kat. No. 4'te gösterilen örneklere göre nispeten daha incelmiş, ancak kısa tutulmuş, içi dolu bir ayağa sahiptir. Gövdenin en şişkin kısmının karında yer aldığı görülmektedir. Bu özellikleriyle, paralellik kurulan materyal

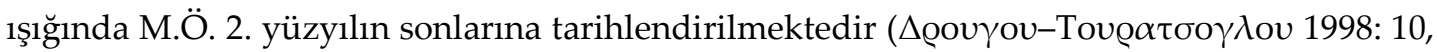
П 1248).

Kat. No. 6'da gösterilen örnek Kat. No. 5'te yer alan örneğe göre ayak kısmı daha uzatılmış olmakla birlikte, içi dolu ve kalın ayak kısmı ve ayaktan gövdeye geçiş profiliyle şişkin karınlı olarak tanımlanacak form içinde değerlendirilebilir ${ }^{27}$. Söz konusu buluntu L 18 açması güneydoğu sektörden ana kaya üzerinden 215.30 kotundan ele geçmiş olup, aynı kottan ele geçen VI. Mithradates Dönemi sikkesi28 ${ }^{28}$ 1şı̆ında bahsi geçen döneme tarihlendirilmiştir.

1.3. Üçüncü grubu kırmızımsı sarı renkli hamura sahip, astar uygulaması olmayan Kat. No. 7'de (Lev. 2/7) gösterilen tek bir örnek oluşturmaktadır. Mezar buluntusu olarak ele geçen bu örnek, ağız kısmı hariç, tüme yakın korunagelmiştir. İçi dolu silindirik, ince ve uzun olan ayağın kaidesi çok hafif dışa doğru açılır şekilde biçimlendirilmiş olup, bu biçimiyle ayakta durması mümkün olmayan bir form göstermektedir. Asimetrik yapısının yanı sıra, astar uygulamasının bulunmaması ve pürüzlü yüzeyiyle de mezar kullanımına yönelik üretildiği anlaşılmaktadır. Uzatılmış boyun ve ayak kısmı ve buna uygun olarak gövdenin de incelmiş formuyla karakterizedir. Paralel materyal üzerinden yapılan değerlendirmeler, (Vogeikoff-Brogan 2000: 295, 317, fig. 21/61; Rotroff 2006: fig. 67/515) MÖ 1. yüzyıl başlarına tarihlenebileceğini göstermektedir.

1.4. Dördüncü grubu kırmızımsı sarı renkli hamura sahip ve kırmızı renkli astarlı Kat. No. 8'de (Lev. 2/8) gösterilen tek bir örnek oluşturmaktadır. Alttan ayak gövde geçişinin

${ }_{27}$ Hellström 1965: 66, pl. 34/171, Hellström, Labraunda örnekleri üzerinden yaptığı değerlendirmede, form açısından paralellik kurduğumuz materyal için tarihlemenin zor olduğunu belirtmektedir.

${ }^{28}$ Söz konusu sikkenin ön yüzünde başında miğferi ile tanrıça Athena, arka yüzünde ise Medusa'nın başını kesen Perseus betimi yer almaktadır. Bu tip sikkeler Imhoof-Blumer tarafından MÖ 105-90 yılları arasına tarihlendirilmektedir Imhoof-Blumer 1912: 169-192.

SEFAD, 2018 (39): 267-292 
olduğu yerden, üstten ise gövdenin orta yerine yakın bir noktadan kırılmış olan parçanın korunan kısımlarından, uzun ve içi tamamen dolu bir ayağa ve gövdenin yukarıya doğru yöneliş açısından şişkinlik oluşturmayan ince bir karna ve buna bağlı olarak daralmış iç hazneye sahip olduğu anlaşılmaktadır. Parça yüzeyindeki astar ince uygulanmış olup, aşınmış olmakla birlikte diğer örneklere göre daha kaliteli olduğu gözlenmektedir. Kazı çalışmaları sırasında birlikte ele geçen kalıp yapımı kabartmalı seramik parçaları (ErolTamer 2014: fig. 22/2; Erol 2015: fig. 8/1; Erol-Tamer 2017: 111-145.) ve paralel bir örnek üzerinden (Dündar 2008: 19,20, 113, Lev. 12. U86) MÖ 1. yüzyıl başına tarihlendirilmiştir.

\section{Kubbe Form Ağız Kenarlı Unguentariumlar}

Hayes tarafından Kıbrıs'ta MÖ 180-160 yıllarına tarihlenen tabakalardan ele geçtiği ve yüzyılın sonuna kadar üretimlerinin devam ettiği belirtilen bir diğer tip kubbe form ağız kenarlı unguentariumlardır. Söz konusu form; kubbe şeklinde ağız kenarına, yüksek bir boyun kısmına, belirgin bir şekilde vurgulanan omuza, kalp biçimli gövde profiline ve geniş tabanlı konik bir kaideye sahiptir (Hayes 1991: 68; Dotterweich 1999: 64; Guz-Zilberstein 1995: 306; Rotroff 2006: 157-158). Dotterweich, Knidos kazılarından yoğun ele geçen bu formun Doğu Akdeniz Bölgesi ile sinırlı olduğunu, ancak arkeometrik analizlerinin üretim merkezi olarak doğrulamadığını belirtmektedir (Dotterweich 1999: 12, 32). Dotterweich, kubbe form ağız kenarlı unguentariumların üretim başlangıcının MÖ 3. yüzyıl içinde biraz daha erkene gidebileceğini, MÖ 2. yüzyılda ise üretiminin en yüksek noktaya ulaştığını ve MÖ 1.yüzyıla kadar devam ettiğini belirtmektedir (Dotterweich 1999: 40, 64).

Kat. No. 9'da (Lev. 2/9) gösterilen örnek kubbe form ağız kenarlı unguentariuma ait bir gövde parçasıdır. Paralel örnekler üzerinden MÖ 2. yüzyıl sonlarına tarihlenmektedir (Dündar 2008: 121, Lev. 14. U121; Dotterweich 1999: Taf. 3 Kat. Nr. 1).

\section{Küresel Gövdeli Unguentariumlar}

Küresel gövdeli unguentariumlar; dışa çekik ve inceltilmiş ağız kenarı ile uzun silindirik dar boyun, küresel gövde, alçak ve küçük çaplı bir kaideyle karakterizedir. Küresel formlu örnekler tüm Akdeniz Havzasında görülmekle birlikte, Likya Bölgesinde bu formun yerel özellikler taşıyan çeşitleri bulunmaktadır (Dündar 2008: 27-30, 127-136; Dündar-Akyol 2017: 174, Fig. 11; Ürkmez-Dündar 2014: 66, Fig. 15; Özdilek 2016: 229).

Kat. No. 10'da (Lev.2/10) tanitılan örnek, küresel gövdeli yerel/bölgesel üretim bir unguentariuma ait ağız ve gövde parçasıdır ${ }^{29}$. Bu tipolojiye giren örnekler, genelde alçak ve küçük çaplı bir kaideye ve çok uzun bir boyuna sahiptir. Boyun kısmı ele geçmemiş olup, kesin yüksekliği bilinmemekle birlikte, dışa çekik ağızlı ve çok alçak olmayan halka bir kaideye sahiptir. Fırınlama nedeniyle kırmızımsı sarı olan hamur rengi, soluk kahverengiye dönüşmüştür. Kabın yüzeyinde astar uygulamasına ait bir iz görülmemektedir. Roma Erken İmparatorluk Dönemine tarihlenebilecek tek örnektir.

${ }^{29}$ Dündar-Akyol 2017: 158-160, 174, fig. 11; Form ve hamur özellikleri bakımından analoji kurulan örneklerden farklılık göstermekte olup, yerel/bölgesel üretim olduğu düşünülmektedir. 


\section{SONUÇ}

Katalogda sunulan sınırlı sayıdaki örnekler üzerinden söz konusu yerleşime ait en erken tarihli unguentariumların MÖ 2. yüzyılın ortalarından daha erkene gitmediği görülmektedir. MÖ 2. yüzyıl ortalarına ait parçalar profil olarak gövdenin en geniş kısmının karına doğru indiği, içi dolu kalın ayaklı ve kaidesi profillendirilmiş örneklerden oluşmaktadır. MÖ 2. yüzyıl sonu-MÖ 1. yüzyıl başına ait örnekler ise boyun ve ayak kısımları uzatılmış, iç hacmi daraltılmış, gövde kısmının şişkinliğin azaldığı bir profille karakterizedir. Cingırt Kayası'nda fusiformlardan farklı olarak kubbe form ağız kenarlı ve küresel gövdeli iki farklı formda unguentariumun ele geçmesi, tipolojik açıdan Akdeniz orijinli olan bu iki tipin Karadeniz coğrafyasında da yerel/bölgesel üretimler olarak yer bulduğunu göstermesi açısından önem arz etmektedir. Paralel örnekler üzerinden yapılan değerlendirmeler, bu çalışmada sunulan örneklerin yerel/bölgesel üretimler olabileceği önerisinde bulunmamızı sağlamaktadır.

Ele geçen unguentariumların arazi üzerindeki dağılımına bakıldığında hem mezar hediyesi olarak, hem de domestik amaçlı kullanıldığı görülmektedir. Ayrıca işlikten ele geçen bir örnek, unguentariumların üretimle ilgili bir aşamada da kullanılmış olabileceği öngörüsünde bulunmamızı sağlamaktadır.

MÖ 1. yy'ın sonlarına doğru cam üfleme tekniğinin yaygınlaşmasına paralel olarak, pişmiş toprak örneklerin yerini cam unguentariumlar almış olup, söz konusu döneme tarihlenen cam unguentarium örneklerinin sayısındaki artış, bu durumun Cıngırt Kayası için de geçerli olduğunu göstermektedir.

\section{SUMMARY}

Cingırt Kayası is located in a region called "Pontos" in Ancient times, which is currently within the borders of Yapraklı village, in the town of Fatsa, city of Ordu in the Eastern Black Sea Region. Sources from the Antiquity talk about Phrourion that were built to control and defend the Eastern Black Sea Region during the reign of Mithradates VI. Based on the excavations conducted predominantly on the summit of Cingirt Kayas1, it is suggested that Cingırt Kayası was part of a security chain that consisted of Phrourion to provide control and defense of the Pontic Region during the reign of Mithradates VI. The materials that this study focuses on are selected samples of unguentarium fragments that were obtained from the summit of Cingirt Kayası. They are presented with their catalogue and plate information, through the evaluation of their typology and chronology based on data from the excavations and comparisons with similar materials. This study also refers to the literature that concentrates on the unguentariums. Moreover, other items found during the excavations that point to a definitive time period, such as coins, have also been used as factors setting a date for the unguentariums. When the distribution of unguentaria found on the peak is examined, it is seen that they are used both as domestic and as a grave gift.

There have been few excavations conducted in the Eastern Black Sea Region, and thus this study aims to share one of the first findings of the unguentariums obtained from Cingirt Kayasi excavations and to contribute to the studies related to unguentariums through the Black Sea Basin. Among the Cingirt finds, the numeric multiplicity of glass unguentariums belonging to the Early Imperial Period have shown that glass has been preferred instead of terra cotta material in the Black Sea region just as in the Mediterranean geography.

SEFAD, 2018 (39): 267-292 


\section{KAYNAKÇA}

Akkaya, Mustafa (1993). "Amisos Antik Kenti Kurtarma Kazısı", III. Müze Kurtarma Kazıları Semineri. 27-30 Nisan 1992, Efes, Ankara: Ankara Üniversitesi Basımevi. 207-218.

Alcock, Joan (1980). "Classical Religious Belief and burial Practice in Roman Britain". Archaeological Journal (137): 50-85.

Anderson-Stojanović, Virginia Ruth (1987). "The Chronology and Function of Ceramic Unguentaria". American Journal of Archaeology (91): 105-122.

Anderson-Stojanović, Virginia Ruth (1992). Stobi: The Hellenistic and Roman Pottery. New Jersey. Princeton University Press.

Arrianus(2005). Arriani Periplus Ponti Euxini, Arrianus'un Karadeniz Seyahati. Türkçe çev. Murat Arslan. İstanbul. Odin Yayıncılık.

Åström, Paul (1967). “Two Unguentaria and an Obol”. Opuscula Atheniensia (7): 187-190.

Atik, Neşe (1995). Die Keramik aus den Südthermen von Perge. IstMitt. Beiheft (40). Tübingen: E. Wasmuth.

Aydıngün, Şengül (2016.10.16). "Bathonea Kazılarında 1400 Yıl Önce Kullanılan Depresyon ve Kalp İlaçları Bulundu". Hürriyet Web.

Baldıran, Asuman (2015). "Stratonikeia'dan Rulet Bezemeli Unguentariumlar". Mustafa Büyükkolancı'ya Armağan. ed. Celal Şimşek, Bahadır Duman, Erim Konakçı. İstanbul. Ege Yayınları. 71-83.

Barag, Dan (1972). "Two Roman Glass Bottles with Remnants of Oil". Israel Exploration Journal (22): 24-26.

Belov, G. D. - Strzeleckji, S. F. - Jakobson, A. L. (1953). "Kvartal XVIII: Raskopki 1941, 1947 i 1948 gg". MatIssIA (34): 160-236.

Berlin, Andrea (1997). "The Plain Wares". In Tel Anafa II, i: The Hellenistic and Roman Pottery, Journal of Roman Archaeology Supplementary Series 10. ed. Sharon C. Herbert. Ann Arbor: Kelly Museum. 1-242.

Bouzek, Jan (1990). Studies of Greek Pottery in The Black Sea Area. Prag. Charles University.

Brun, Jean Pierre (2000). "The Production of Perfumes in Antiquity: The Cases of Delos and Paestum". American Journal of Archaeology (104/2): 277-308.

Bucovala, Mihai (1967). Necropole elenistice la Tomis. Constanta. Muzeul Regional de Archeologie Dobrogea.

Buzoianu, Livia - Bărbulescu, Maria (2008). Albeşti. Monografie Arheologică I. Constanța: Muzeul de Istorie Nationala şi Arheologie.

Camilli, Andrea (1999) Ampullae. Balsamari Ceramici di etá Ellenistica e Romana. Roma. Fratelli Palombi.

Chidiroglou, Maria (2015). "Krüge, einhenklige Schalen, Siebflaschen, Olpen und Unguentarien". Der versunkene Schatz Das Schiffswrack von Antikythera. ed. Andrea Bignasca, Maria Lagogianni-Georgakarakos, Nikolaos Kaltsas, Elena Vlachogianni. Basel: 198-205.

Christiensen, Aristea Papanicolaou - Johansen, Charlotte Friis (1971). Hama: fouilles et recherches de la Fondation Carlsberg (1931-1938) III-2. Les poteries hellénistiques et les terres sigillées orientales. Copenhague.

Civelek, Aynur (2006). "Stratonikeia-Akdağ Nekropolisi'nden Bir Mezar". Anadolu/Anatolia (30): 47-64.

Civelek, Aynur (2012). "Mezar Stelleri Üzerindeki Unguentariumlar Üzerine Gözlemler". Arkeoloji ve Sanat (141): 77-90. 
Çaylak-Türker, Ayşe (2005). “Myra'da Aziz Nikolaos'un Yağ Kültüyle İlişkili Seramik Kaplar". Adalya (VIII): 311-328.

Demargne, Pierre (1958). Les Piliers Funéraires, Fouilles de Xanthos I: Paris: Klincksieck.

Dioscorides. De Materia Medica: Being an Herbal with Many Other Medicinal, Trans. by Tess Anne Osbaldeston. South Africa Johannesburg: İbidis Press,

Dotterweich, Ulrich (1999). Unguentarien mit kuppelförmiger Mündung aus Knidos. KnidosStudien Bd 1. Möhnesee.

Drougou, Stella (1991). Hellenistic Pottery From Macedonia. Thessaloniki: Aristotle University of Thessaloniki.

Dusenbery, Elsbeth B. (1998). Samothrace, The Necropolis and Catalogues of Burials and Catalog of Objects by Categories, Samothrace II. New Jersey. New Jersey Princeton.

Dündar, Erkan - Akyol, Ali Akın (2017). "Unguentarium Production at Patara and a New Unguentarium Form: Archaeological and Archaeometric Interpretation". Adalya (20): 157-179.

Dündar, Erkan (2008). Patara Unguentariumları, Patara IV.1. İstanbul: Ege Yay.

Edwards, George Roger (1965). "The Antikythera Shipwreck Reconsidered", Transactions of the American Philosophical Society (55-3): 18-27.

Er, Yasemin (2004). Klasik Arkeoloji Sözlüğ̈̈. Ankara: Phoenix Yayınevi.

Erol, Ayşe Fatma - Tamer, Deniz (2014). "The Excavation at Cingirt Kayası: Assessments in the Light of Archaeological Findings". Turkey Through The Eyes of Classical Archaeologists. ed. Erik Hrnčiarik. Trnava: Trnavská Univerzita V Trnave Universitas Tyrnaviensis. 73-98.

Erol, Ayşe Fatma - Tamer, Deniz (2017). "Ordu-Fatsa Cıngırt Kayası Kazısı Hellenistik Dönem Kalıp Yapımı Kabartmalı Kaseleri". Anadolu/Anatolia (43): 111-145.

Erol, Ayşe Fatma (2013). "Fatsa İlçesi Arkeolojik Yüzey Araştırması 2011", 30. Araştırma Sonuçları Toplantısı, Vol 2. 28 Mayıs- 01 Haziran 2012, Çorum. Ankara: 183-196.

Erol, Ayşe Fatma (2014). “Ordu İli Fatsa İlçesi Cıngırt Kayası Kazısı 2013”, 36. Kazı Sonuçları Toplantısl, Cilt. I, 02-06 Haziran 2014, Gaziantep. Ankara: 383-400.

Erol, Ayşe Fatma (2015). "New Findings on the History and Archaeology of the Eastern Black Sea Region of Turkey: The Excavation at Cingirt Kayası". Fifth International Congress on Black Sea Antiquities. 17-21 Eylül 2013. Belgrad: 451-460.

Erten-Yağcı, Emel (1993). Başlangıcından Geç Antik Dönem Sonuna Kadar Anadolu'da Cam. Ankara Üniversitesi Sosyal Bilimler Enstitüsü Arkeoloji ve Sanat Tarihi Anabilim Dalı Yayınlanmamış Doktora Tezi. Ankara.

Firat, Murat (2012). "Isparta Müzesi Seramik Koleksiyonu: Unguentaria”. Birinci Ulusal Psidia Araştırmaları Sempozyumu. 5-6 Kasım 2012. Isparta. 294-311.

Firat, Nalan (2003). "Perge Konut Alanı Kullanım Keramiği". Les céramiques en Anatolie aux époques héllenistique et romaine. Varia Anatolica XV. ed. Catherine AbadieReynal. İstanbul-Paris Institut Français d'Études Anatoliennes d'Istanbul. 91-95.

Forti, Lidia (1962). "Gli unguentari del primo periodo ellenistico". Rendiconti della Accademia di archeologi., lettere e belle arti di Napoli (37): 143-155.

Gaius Plinius Secundus. Naturalis Historia. Pliny Natural History. English Trans. by Harris Rackham,Vol. I-V Books 1-19. London: William Heinemann Ltd; Cambridge, Massachusetts: Harvard University Press: The Loeb Classical Library.

Gaucker, Paul (1915). Nécropolés Puniques de Carthage 1-2. Paris.Picard.

SEFAD, 2018 (39): 267-292 
Greenewalt, Crawford Hallock Jr. - Sullivan, Donald G. - Ratte, Christopher J. - Howe, Thomas N. (1983). "Sardis 1981 and 1982". Türk Arkeoloji Dergisi (XXVI-2): 155-215.

Grozdanova, Vera Bitrakova (1990). “Les Caractéristiques de la Céramique Hellénistique de

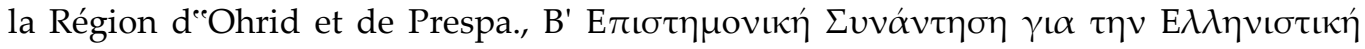

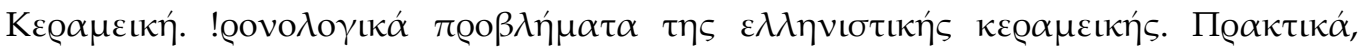
Pódos 22 - 25 Ma@тíov 1989, 1990. 66-73.

Guz-Zilberstein, Bracha (1995). "The Typology of the Hellenistic Coarse Ware and Selected Loci of the Hellenistic and Roman Periods. Excavations at Dor, Final Report Volume I B, Areas A and C: The Finds. ed. Anna Belfer- Cohen, Amnon Ben-Tor, Yoram Tsafrir. Jarusalem: 289-433.

Günay, Gamze (1989). İzmir Müzesi'nde Bulunan Unguentariumlar. Yüksek Lisans Tezi. İzmir: Ege Ü.

Günay-Tuluk, Gamze (1999). "Die Unguentarien im Museum von İzmir". Anatolia Antiqua (VII): 127-166.

Gürler, Binnur (1994). Metropolis'in Hellenistik Dönem Seramiği. Doktora Tezi. İzmir: Ege Ü.

Handberg, Soren - Petersen, Jane Hjarl (2010). "D Black-glossed Pottery". The Lower City of Olbia (Sector NGS) in the 6th Century BC to the 4th Century AD. Black Sea Studies 13. ed. Nina A. Lejpunskaja - Pia Guldager Bilde - Jakob Munk Højte - Valentina V. Krapivina - Sergej Dmitrievic Kryžickij. Aarhus: 185-260.

Harden, Donald Benjamin (1969). "Ancient Glass, II: Roman". Archaeological Journal (126): 4477.

Hayes, John Walker (1971). "A New Type of Early Christian Ampulla". British School at Athens (66): 243-248.

Hayes, John Walker (1991). The Hellenistic and Roman Pottery. Paphos III. Nicosia: Imprinta LTD.

Hayes, John Walker (1997). Handbook of Mediterranean Roman Pottery. London: British Museum Press.

Heimberg, Ursula (1982). Die Keramik des Kabirions (Das Kabirenheiligtum bei Theben iii), Berlin: W. de Gruyter.

Hellström, Pontus (1965). Pottery of Classical and Later Date Terracotta Lamps and Glass, Labraunda, Swedish Excavations and Researches, Vol. II Part 1. Lund: C. W. K. Leerup.

Hermary, Antoine - Panayotova, Krastina - Baralis, Alexandre - Riapov, Atila - Damyanov, Margarit (2010). Apollonia du Pont (Sozopol), La nécropole de Kalfata (Ve-IIIe s. av. J.-C.). Fouilles Franco-bulgares (2002-2004). Paris: Errance.

Imhoof-Blumer, Friedrich (1912). “Die Kupferprragung des Mithradatischen Reiches und undere Münzen des Pontos und Paphlagoniens". Numismatische Zeitschrift (XLV): 169192.

Indgjerd, Hallvard (2014). The Grave Goods of Roman Hierapolis An Analysis of The Finds From Four Multiple Burial Tombs. Unpublished Master's Thesis. University of Oslo.

Ivanov, Teofil (1963). "Antična keramika ot nekropola na Apolonia". Apolonija. Razkopkite na nekropola na Apolonija prez 1947-1949 g. ed. Ivan Venedikov. Sofia: 65-273.

Ivchenko, Andrey (2015). "Ground burial crypt with parian amfora at Olbian necropolis". Ancient World and Archaeology Materials of the IVth International Conference Word and Artifact: Interdisciplinary Approaches to Study of Ancient History. September 1921, 2014. Ancient World and Archaeology 17. Saratov: 253-271.

İşkan, Havva - Çevik, Nevzat (1995). “Die Grüfte von Patara”. Lykia (II): 187-216. 
Jones, Frances Follin (1950). "The Pottery". In Excavations at Gözlü Kule, Tarsus. Vol. I: Hellenistic and Roman Periods. ed. Hetty Goldman. New Jersey: Princeton University Press. 149-296.

Kahane, Pnuel (1952). "Pottery Types from the Jewish Ossuary-Tombs Around Jerusalem: An Archaeological Contribution on the Problem of the Hellenization of Jewry in the Herodian Period". Israel Exploration Journal (2): 125-139.

Kaposina, S. M. (1959). “Necropol' v rajone poselka im. Vojkova bliz Kerci”. MatIssIA (69): 108-153.

Karjaka, Alexander V. (2010a). "G Greyware pottery". The Lower City of Olbia (Sector NGS) in the 6th Century BC to the 4th Century AD, Black Sea Studies 13. ed. Nina A. Lejpunskaja - Pia Guldager Bilde - Jakob Munk Højte - Valentina V. Krapivina - Sergej Dmitrievic Kryžickij. Aarhus: 289-304.

Karjaka, Alexander V. (2010b). "H Redware pottery". The Lower City of Olbia (Sector NGS) in the 6th Century BC to the 4th Century AD, Black Sea Studies13. ed. Nina A. Lejpunskaja - Pia Guldager Bilde - Jakob Munk Højte - Valentina V. Krapivina - Sergej Dmitrievic Kryžickij. Aarhus: 305-324.

Kasaev, Sergei (2002). "Commonware". Panskoye I. ed. Lise Hannestad - Vladimir F. Stolba Alexander N. Sceglov. Aarhus: 150-179.

Khairy, Nabil Ibrahim (1980). "Nabatean Piriform Unguentaria". The Bulletin of the American Schools of Oriental Research (240): 85-91.

Knigge, Ursula (1976). Der Südhügel, Kerameikos IX. Berlin: W. de Gruyter.

Korkut, Taner - Işın, Gül (2015). "Fethiye Müzesi'nden Bir Grup Tlos Seramiği". Seydikemer Kaymakamlığı Yayınları I. Arkeoloji, Epigrafi, Jeoloji, Doğal ve Kültürel Peyzaj Yapisiyla Tlos Antik Kenti ve Teritoryumu. ed. Taner Korkut. Ankara: 213-228.

Kotitsa, Zoi (1998). Hellenistische Keramik im Martin von Wagner Museum der Universität Würzburg. Würzburg: Ergon Verlag.

Körsulu, Hatice (2011). “Nagidos Unguentariumları”. Tüba-Ar (14): 69-86.

Kunisch, Norbert (1972). "Grabfunde aus dem Stadtgebiet von Bergama". Pergamon Gesammelte Aufsätze, Pergamenische Forschungen 1. ed. Erich Boehringer. Berlin: 94107.

Kurtz, Donna Carol - Boardman, John (1971). Greek Burial Customs. Ithaca - New York: Cornell University Press.

Laflı, Ergun (2003). Studien Zur Hellenistischen, Kaiserzeitlichen und Spätantikfrühbyzantinischen Tonunguentarien aus Kilikien und Psidien (Süd Türkei): Der Forschungsstand und Eine Auswahl von Fundobjekten aus den Örtlichen Museen. Doktora Tezi. Köln.

Lapp, Paul Wilbert (1961). Palestinian Ceramic Chronology 200 B.C. - A.D. 70. New Haven.

Le Roy, Christian (2001-2002). "La Nécropole du Létoon de Ksanthos". Güneybatı Anadolu' da Mezar Tipleri ve Ölü Kültü, Uluslararası Kolokyum, 4.-8. Ekim 1999, Lykia VI. ed. Havva İşkan, Fahri Işık. Antalya: 247-260.

Lomtadze, Georgij - Zuravlev, Denis (2014). "Hellenistic Pottery from the Necropolis of Olbia Pontike". Pottery, Peoples and Places. Study and Interpretations of Late Hellenistic Pottery, Black Sea Studies 16. ed. Pia Guldager Bilde - Mark Lawall. Aarhus: 175-197. 
Marcus Tullius Cicero. De finibus bonorum et malorum. On the Ends of Good and Evil. English Trans. by Paul. Nixon, London: William Heinemann; New York: The Macmillan Co., The Loeb Classical Library.

Marcus Tullius Cicero. De Officiis, On Duties. English Trans. by Walter Miller, London: William Heinemann: New York: The Macmillan Co., The Loeb Classical Library.

Mordvinceva, Valentina (2005). "The Royal Grave from the Time of Mithridates Eupator in the Crimea". Chronologies of the Black Sea Area in the Period C. 400-100 BC. Black Sea Studies 3. ed. Vladimir F. Stolba, Lise Hannestad. Aarhus: 275-285.

Myers, John Nowell Linton (1914). Handbook of the Cesnola Collection of Antiquities from Cyprus. New York.

Nohlen, Klaus - Radt, Wolfgang (1978). Kapıkaya. Ein Felsheiligtum bei Pergamon, Altertümer von Pergamon XII. Berlin: Walter de Gruyter.

Oakley, John H. (2004). Picturing Death in Classical Athens: The Evidence of the White Lekythoi. Cambridge: Cambridge University Press.

Olshausen, Eckart - B1ler, Joseph (1984). Historisch-Geographische Aspekte der Geschichte des Pontischen und Armenischen Reiches. Teil 1: Untersuchungen zur historischen Geographie von Pontos unter den Mithridatien, Beihefte zum Tübinger Atlas des Vorderen Orients 29/1. Wiesbaden.

Özdilek, Banu (2016). "2009-2012 Andriake Kazılarından Ele Geçen Unguentarium, Şişe, Lykion ve Mortar Örnekleri". Olba (XXIV): 217-265.

Özhanlı, Mehmet - Şen, Zeliha (2007). “Side'den Geç Roma Unguentariumları". Ege Üniversitesi Arkeoloji Dergisi (X): 141-155.

Özüdoğru, Şükrü - Dündar, Erkan (2007). “Kibyra Geç Roma-Erken Doğu Roma Dönemi Mühürlü Unguentariumları". Olba (XV):145-177.

Parovich-Peshikan, Maja (1974). Nekropol Olvii Ellenisticeskogo Vremini. Kiev.

Pemberton, Elizabeth. G. (1985). “Ten Hellenistic Graves in Ancient Corinth". Hesperia (54): 271-307.

Pfuhl, Ernst - Möbıus, Hans (1997). Die Ostgriechischen Grabreliefs. Mainz am Rhein: Verlag Philipp von Zabern

Podossinov, Aleksander Vasil'evič (2012). "Bithynia, Paphlagonia and Pontus on the Tabula Peutingeriana". The Black Sea, Paphlagonia, Pontus and Phrygia in Antiquity: Aspects of Archaeology and Ancient History, British Archaeological Reports International Series 2432. ed. Gocha Revazi Tsetskhladze. Oxford: 203-206.

Quintus Horatius Flaccus. Satires, Epistles, Ars Poetica. English Trans. by H. Rushton Fairclough, London: William Heinemann Ltd; Cambridge: Massachusetts: Harvard University Press. The Loeb Classical Library.

Rotroff, Susan Irene (1984). "The Origins and Chronology of Hellenistic Gray Unguentaria". American Journal of Archaeology (88): 234-264.

Rotroff, Susan Irene (1997). Hellenistic Pottery Athenian and Imported Wheelmade Table Ware and Related Material, The Athenian Agora XXIX. New Jersey: New Jersey Princeton.

Rotroff, Susan Irene (2006). Hellenistic Pottery The Plain Ware, The Athenian Agora XXXIII. New Jersey: New Jersey Princeton.

Saraçoğlu, Aslı (2011). "Hellenistic and Roman Unguentaria from the Necropolis os Tralleis". Anadolu/Anatolia (37). 1-42.

Smetana-Scherrer, Rudolfine (1982). "Spätklassische und hellenistische Keramik". Alt Ägina II-1. ed. H. Walter. Mainz: 56-91. 
Smith, William(1870). ed. Dictionary of Greek and Roman Antiquities, London.

Sparkes, Brian A. - Talcott, Lucy (1970). Black and Plain Ware of the Sixth, Fifth and Fourth Centuries B.C., The Athenian Agora XII. New Jersey: New Jersey Princeton.

Stern, Eva Marianne (2001). Roman, Byzantine and Early Medieval Glass 10 BCE - 700 CE. Ernesto Wolf Collection. New York: Hatje Cantz Publishers.

Strabon. Geographika. The Geography of Strabo. (English Trans. by H. L. Jones), In eight volumes, Vol V, London: William Heinemann Ltd; Cambridge, Massachusets: Harvard University Press, 1961. The Loeb Classical Library.

Şaroğlu, Gülcan (2010). Kappadokia, Pontos, Paphlagonia Ve Kilikia Bölgeleri'nin Dă̆ları. Yüksek Lisans Tezi. Antalya: Akdeniz Ü.

Şenyurt, Süleyman Yücel - Akçay, Atakan (2016). "Kurul Kalesi (Ordu) 6. Mithradates Dönemi Yerleşimi Üzerine Ön Değerlendirmeler". Seleucia ad Calycadnum (III): 221-248.

Şimşek, Celal - Duman, Bahadır (2007). “Laodikeia'da Bulunan Geç Antik Çağ Unguentariumları". Adalya (X): 285-307.

Tavukçu, Zerrin Aydın (2006). Parion Nekropolü 2005 Yılı Buluntuları. Doktora Tezi. Erzurum: Atatürk Ü.

Thompson, Homer Amstrong (1934). "Excavations in the Athenian Agora Fifth Reports Two Centuries of Hellenistic Pottery". Hesperia (III-4): 311-476.

Tırpan, Ahmet Adil - Söğüt, Bilal (2001). "Lagina Hekate Temenosu 1999 Yılı Çalışmaları”. Kazı Sonuçları Toplantısı 22/2, Ankara: T.C. Kültür ve Turizm Bakanlığı Kültür Varlıkları ve Müzeler Genel Müdürlüğü Yayınları. 299-310.

Titus Maccius Plautus. Persia. English Trans. by Harris Rackham, In five volumes. Vol III. London: William Heinemann; New York G. P. Putnam's Sons Ltd, The Loeb Classical Library.

Tzanavari, Katerina (2010). "Funerary assemblages of late imperial pottery from Lete,

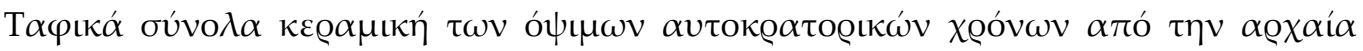

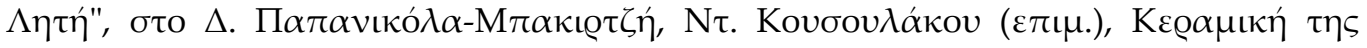

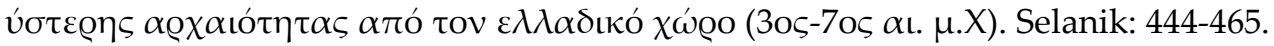

Ünan, Serdar (2010). Samsun ve Çevresi Mezar Tipleri ve Ölü Gömme Adetleri (MÖ III. Bin- MS IV. YY.). Yüksek Lisans Tezi. Kütahya: Dumlupınar Ü.

Ürkmez, Özden - Dündar, Erkan (2014/1). "Remarks on the Possible Uses of the Perfumed Oils, Ointments, and its Containers in the Cult of Dead from the fourth century BC to the second century AD". Journal of Intercultural and Interdisciplinary Archaeology: 51-71.

Vaag, Leif Erik - Nørskov, Vinnie - Lund, John (2002). Maussolleion at Halikarnassos, Volume 7: Reports of the Danish Archaeological Expedition to Bodrum-The Pottery. Aarhus.

Vessberg, Olof - Westholm, Alfred (1956). The Hellenistic and Roman Periods in Cyprus, The Swedish Cyprus Expedition. Vol. IV-3. Stockholm.

Vogeikoff-Brogan, Natalia (2000). "Late Hellenistic Pottery in Athens: A New Deposit and Further Thoughts on the Association of Pottery and Societal Change". Hesperia (69): 293333.

Weber, Ekkehard (ed.) (1976). Tabula Peutingeriana, Codex Vindobonensis 324, vollständige Faksimile Ausgabe im Originalformat, Akademische Druck- u. Verlagsanstalt. Austria Graz.

Weimert, Helmut (1984). Wirtschaft als landschaftsgebundenes Phänomen. Die Antike Landschaft Pontos: Eine Fallstudie: Frankfurt am Main: P. Lang.

SEFAD, 2018 (39): 267-292 
Wilson, David Raoul (1960). The Historical Geography of Bithynia, Paphlagonia and Pontos in the Greek and Roman Periods. B. Litt. Thesis. Oxford University.

Wiseman, James - Mano-Z1ssı, Djordje (1976). "Stobi: A City of Ancient Macedonia". Journal of Field Archaeology (3): 269-302.

Yaşar, Ali (2010). Milet Müzesi'nde Bulunan Hellenistik ve Roma Dönemi Unguentariumlar. Yüksek Lisans Tezi. Aydın: Adnan Menderes Ü.

Yıldız, Volkan (2016). "Akhisar Arkeoloji Müzesi'nde Bulunan Unguentariumlar". Manisa: СВÜ Sosyal Bilimler Dergisi (1i Cilt 14): 1-24.

Zajcev, Jurij P. (2005). "Absolute and relative chronology of Scythian Neapolis in the 2nd century BC.". Chronologies of the Black Sea Area in the Period c. 400-100 BC., Black Sea Studies 3. ed. Vladimir F. Stolba, Lise Hannestad. Aarhus: 259-73.

Zuravlev, Denis - Demidenko, Sergey Viktorovich - TREJSTER, Mikhail (1997). "Kruglij Kurgan: Eine Gesamtvorlage des Materials aus den Grabungen des Barons V.G. von Tiesenhausen". Eurasia Antiqua (3): 409-435.

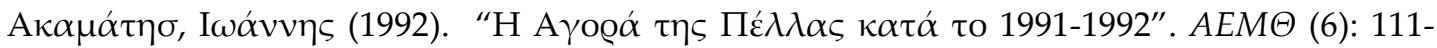
125.

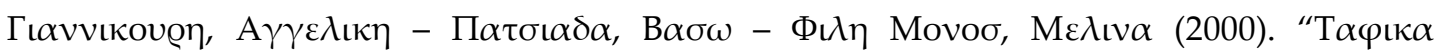

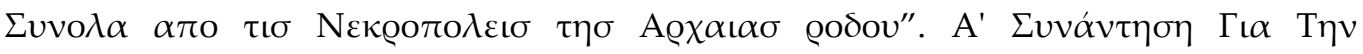

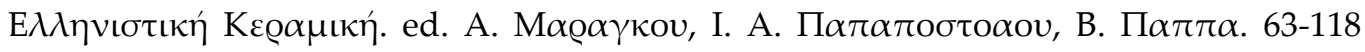

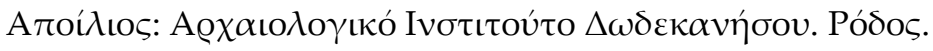

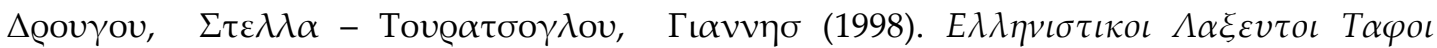

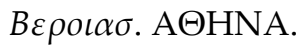


KATALOG

Katalog No: 1 (Lev. 1/1) Envanter No: FCK12.K16.01.32

Alan/Açma/Derinlik: K16 Açması/GD sektör/f-j-6-10 Plankare/ Tabaka/216.10-215.90

Ölçüler: Taban Ç: $4 \mathrm{~cm}$. Korunan Y: $6.8 \mathrm{~cm}$ CK: $0.7 \mathrm{~cm}$

Hamur Rengi: 10 YR 7/3 (Very Pale Brown) Yüzey Rengi: 10 YR 7/2 ( Light Gray) Astar Rengi: 10 YR 3/1 (Very Dark Gray)

Hamur Tanımı: Yumuşak bir hamur dokusuna sahip olup, çok az ince boyutlarda kum, mika, kireç, az ve ince şamot katkılı.

Form Tanımı: İ̆g formlu. İçi dolu ve kalın ayak kısmı kaideyle son bulmaktadır. Kabın diğer kısımları eksiktir.

Referans: Bucovala 1967: 84, Fig. 51/a - 123, Fig. 78/c

Tarih: MÖ 2. yüzyılın ortaları.

Katalog No: 2 (Lev. 1/2) Envanter No: FCK12.K16.01.31

Alan/Açma/Derinlik: K16 Açmas//GD sektör/g-7 Plankare/I. Tabaka/216.06

Ölçüler: Taban Ç: $4.1 \mathrm{~cm}$ Gövde Ç: $7.6 \mathrm{~cm}$. Korunan Y: $15.3 \mathrm{~cm}$ CK: $0.5 \mathrm{~cm}$

Hamur Rengi: 10 YR 8/4 (Very Pale Brown) Yüzey Rengi: İç: 10 YR 7/2 (Light Gray) Dış: 10 YR 8/3 (Very Pale Brown) Astar Rengi: 10 YR 5/1 (Gray)

Hamur Tanımı: Yumuşak bir hamur dokusuna sahip olup, az miktarda ve çok ince kum, mika, kireç; çok az, ince ve iri boyutlu şamot katkıll.

Form Tanımı: İ̆̆ formlu. Gövdeye geçiş kısmında 2 adet yatay yiv bulunan unguentariumun boyun-gövde, gövde-ayak ve ayak-kaide kısımlarına ait 3 parça birleştirilerek, form kısmen tümlenmiştir. İçi dolu ve kalın ayak kısmı yivli bir kaideyle son bulmaktadır. Şişkin gövdeye sahip olup, keskin olmayan bir omuz profiliyle boyna geçiş yapmaktadır. Boyun ve ağız kısmı eksiktir. Aynı döneme tarihlenen benzer formlar üzerinden değerlendirildiğinde, boynun ağız kısmına doğru genişleyerek uzadığı önerilebilmektedir.

Referans: Rotroff 2006: Fig. 64/448; Zuravlev ve diğ. 1997: 419, Abb. 7/6; Civelek 2006: 57, Çiz. 7.

Tarih: MÖ 2. yüzyılın ortaları.

Katalog No: 3 (Lev. 1/3) Envanter No: FCK12.K17.02.110

Alan/Açma/Derinlik: K17 Açmasi/KD sektör/f-j-1-5 Plankare/I. Tabaka/215.66-215.24

Ölçüler: Taban Ç: $3.4 \mathrm{~cm}$. Korunan Y: $3.5 \mathrm{~cm}$ Ayak K: $2.1 \mathrm{~cm}$

Hamur Rengi: 5 YR 6/6 (Reddish Yellow) Yüzey Rengi: 5 YR 7/6 (Reddish Yellow) Astar Rengi: 5 YR 7/6 (Reddish Yellow).

Hamur Tanımı: Sert bir hamur dokusuna sahip. Çok az çok ince kum, kireç, mika ve çok az ince şamot katkılı.

Form Tanımı: İğ formlu. İçi dolu ve kalın ayak kısmı kaideyle son bulur. Taban düz olmayıp hafif konkavlık oluşturmaktadır. Diğer kısımları korunmamıştır.

Referans: Anderson-Stojanović 1992: Pl. 67/564, 565; Indgjerd 2014: 2/56, Tomb: T159d, Find no. 2001/10; Knigge 1976: Taf. 69/1-388/1.

Tarih: MÖ 2. yüzyılın 2. yarısı.

Katalog No: 4 (Lev. 1/4) Envanter No: FCK13.K15.02.63

Alan/Açma/Derinlik: K15 Açması/GD sektör/f-i-10 Plankare/I. Tabaka/215.78-215.56

SEFAD, 2018 (39): 267-292 
Ölçüler: Taban Ç: $4.2 \mathrm{~cm}$. Korunan Y: $3 \mathrm{~cm}$ Ayak K: $2.1 \mathrm{~cm}$

Hamur Rengi: 5 YR 7/6 (Reddish Yellow) Yüzey rengi: 5 YR 7/8 (Reddish Yellow) Astar Rengi: 10 R 4/8 (Red)

Hamur Tanımı: Kötü pişmiş, yumuşak bir hamur dokusuna sahiptir. Çok az çok ince kum, kireç, mika ve çok az ince şamot katkıll.

Form Tanımı: İğ formlu. Kaide ve ayak kısmının bir bölümü korunmuştur. Ayağın içi dolu ve nispeten kalındır. Kalın ayak kısmı yivli ve tabanında konkavlık oluşturan bir kaideyle son bulmaktadır.

Referans: Bucovala 1967: 64, Fig. 40/b - 122, Fig. 78/e; Lomtadze-Zuravlev 2014: 187, Fig. 8/9

Tarih: MÖ 2. yüzyılın son çeyreği.

Katalog No: 5 (Lev. 1/5) Envanter No: FCK12.K16.01.36

Alan/Açma/Derinlik: K16 Açması/GD Sektör/f-j 6-10 Plankare/ Yüzey Dolgu/216.25216.06

Ölçüler: Taban Ç: $3.5 \mathrm{~cm}$. Gövde Ç: $7.5 \mathrm{~cm}$. (yaklaşık) Gövde Y: 10.9 cm Gövde Omuz Parçası Y: $6 \mathrm{~cm}$. CK: $0.7 \mathrm{~cm}$

Hamur Rengi: 2.5 YR 6/8 (Light Red) Yüzey Rengi: İç: 7.5 YR 6/4 ((Light Brown) Diş: 5 YR 7/8 (Reddish Yellow) Astar Rengi: 2.5 YR 4/6 (Red)

Hamur Tanımı: Kötü pişmiş ince nitelikli, yumuşak bir hamur dokusuna sahip olup, çok miktarda çok ince boyutlarda kum, mika, az ve ince kireç ve az, ince ve iri boyutlu şamot katkısına sahiptir.

Form Tanımı: İğ formlu unguentariumun boyun-gövde, gövde-ayak ve kaide kısmına ait 3 parça birleştirilerek form kısmen tümlenmiştir. İçi dolu ve kalın ayak kısmı yivli bir kaideyle son bulmaktadır. Gövdenin en şişkin kısmı karında yer alıp, boyun ve ağız kısmı eksiktir. Nispeten daha incelmiş fakat kısa tutulmuş bir ayağa sahiptir. Ayak kısmı düz bir tabana sahip olan yivli bir kaideyle son bulmaktadır.

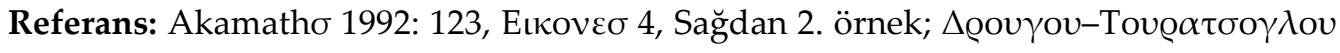
1998: 10, П 1248.

Tarih: MÖ 2. yüzyılın sonu.

Katalog No: 6 (Lev. 1/6) Envanter No: FCK12.L18.02.185

Alan/Açma/Derinlik: $\quad$ L18 Açması/GD sektör/f-j-6-10 Plankare/I. Tabaka (Anakaya)/215.30-215.14

Ölçüler: Taban Ç: $3.6 \mathrm{~cm}$. Korunan Y: $9.2 \mathrm{~cm}$ CK: $0.6 \mathrm{~cm}$

Hamur Rengi: 7.5 YR 7/4 (Pink) Yüzey Rengi: İç: 10 YR 8/4 (Very Pale Brown) Diş: 5 YR 7/6 (Reddish Yellow) Astar Rengi: -

Hamur Tanımı: Yumuşak bir hamur dokusuna sahip. Fırınlamadan kaynaklanan iç ve dış yüzey arasında belirgin renk farklılığı görülmektedir. Astar korunmamıştır. Çok ince çok az kum ve beyaz mika, kireç ve çok az ince ve iri boyutlu şamot katkılı.

Form Tanımı: İ̆g formlu. Şişkin bir gövdeye sahip olup, gövdenin iç kısmında ayağın bitiş noktasından itibaren kalın yivlerle oluşturulmuş ve gövde ortasına doğru gidildikçe incelen basamaklı bir profil oluşturulmuştur. U5'teki örneğe göre ayak kısmı daha uzatılmış olmakla birlikte, nispeten hala kalındır. Ayak kısmı düz bir tabana sahip yivli bir kaideyle son bulmaktadır.

Referans: Hellström 1965: 66, Pl. 12, 34/171. 
Tarih: MÖ 2. yüzyılın sonu, M.Ö. 1. yüzyılın başı.

Katalog No: 7 (Lev. 2/7) Envanter No: FCK13.P20.02.51

Alan/Açma/Derinlik: P20 Açması/GD sektör/i-10 Plankare/212.06

Ölçüler: Taban Ç: $1.9 \mathrm{~cm}$. Gövde Ç: $6.2 \mathrm{~cm}$. Korunan Gövde Y: $12.8 \mathrm{~cm}$ Boyun Y: 5.7 cm CK: $0.3 \mathrm{~cm}$.

Hamur Rengi: 7.5 YR 6/6 (Reddish Yellow) Yüzey Rengi: 7.5 YR 6/4 ( Light Brown) Astar Rengi: -

Hamur Tanımı: Sert bir hamur dokusuna sahip olup, çok miktarda çok ince boyutlarda kum ve mika, az miktarda ince kireç ve şamot katkılı.

Form Tanımı: İğ formlu unguentariumun boyun ve gövde-ayak kısmına ait 2 parça birleştirilerek form kısmen tamamlanmıştır. İçi dolu, silindirik, ince ve uzun ayağın tabanı çok az dışa doğru açılır. Gövde, uzun boyun ve ayağa uygun olarak incelmiş omuz vurgulanmadan boyna geçiş yapmıştır. İnce ve uzun boyun kısmı ağız kısmına doğru gidildikçe artık belirsiz bir genişleme yapar. Ağız kısmı korunmamıştır.

Referans: Vogeikoff-Brogan 2000: 317, Fig. 21/61; Guz-Zilberstein 1995: Fig. 6.26/29; Karjaka 2010: Pl. 220/G-140; Chidiroglou 2015: 201, Abb. 2/üst sira soldan 5. örnek; Bouzek 1990: 63, Fig. 17/7, 8; Rotroff 2006: Fig. 67/515; Edwards 1965: 22, Fig. 11; Christiensen-

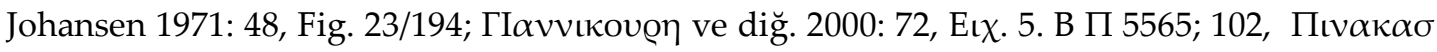
17. $\alpha$ П 5272.

Tarih: MÖ 2. yüzyıl sonu -M. Ö. 1.yüzyıl başı.

Katalog No: 8 (Lev. 2/8) Envanter No: FCK12.K16.02.149

Alan/Açma/Derinlik: K16 Açması/GD sektör/f-j-6-10 Plankare/I. Tabaka II. Evre/215.87-214.97

Ölçüler: Ç: - cm. Korunan Y: 6.9 cm CK: $0.6 \mathrm{~cm}$

Hamur Rengi: 5 YR7/6 (Reddish Yellow) Yüzey Rengi: İ̧: 7.5 YR7/4 (Pink) Diş: 5 YR 7/4 (Pink) Astar Rengi: 2.5 YR 5/8 (Red).

Hamur Tanımı: Sert bir hamur yapısına sahip, iyi pişmiş, çok ince çok az kum, kireç ve mika, çok az ince şamot katkılı.

Form Tanımı: İki parçanın birleştirilmesiyle oluşturulmuş, ĭg formlu bir unguentariuma ait gövde parçası. Altta ayak gövde geçişinin olduğu yerden, üstte ise gövdenin orta yerine yakın bir noktadan kırılmış olan parçanın korunan kısımlarından kalın ve içi dolu bir ayağa ve gövdenin geliş şeklinden çok şişkin olmayan bir gövdeye sahip olduğu anlaşılmaktadır. Ayrıca ayaktan gövdeye geçişin olduğu iç kısımda boşluk oluşturulmayıp, iç hacim azaltılarak neredeyse yuvarlağa yakın bir iç boşluk oluşturulmuştur. Diğer kısımlarının eksik olması nedeniyle, formun mevcut özellikleri üzerinden benzer örnekler verilmiştir.

Referans: Dündar 2008: 19, 20, 113, Lev. 10. U86; Saraçoğlu 2011: 24, Cat. No. 27/U27; Kunisch 1972: 101, Abb. 7/1-2.

Tarih: MÖ 1. yüzyıl başı

Katalog No: 9 (Lev. 2/9) Envanter No: FCK13.L16.02.70

Alan/Açma/Derinlik: L16 Açması/GB sektör/b-6 Plankare/I. Tabaka/215.73

Ölçüler: Gövde Ç: $7.8 \mathrm{~cm}$. Korunan Y: $8.7 \mathrm{~cm}$. CK: $1 \mathrm{~cm}$. 
Hamur Rengi: 5 YR 6/6 (Reddish Yellow) Yüzey Rengi: İç: 5 YR 7/6 (Reddish Yellow) Dış: 7.5 YR 7/4 (pink) Astar Rengi: -

Hamur Tanımı: İnce nitelikli sert bir hamur dokusuna sahip olup, çok az miktarda ve çok ince boyutlarda mika, Çok az ve ince kireç, çok ince kum, çok az ince ve iri boyutlu şamot katkısı içermektedir.

Form Tanımı: Fusiform unguentariuma ait bir gövde parçası, üstte boynun başlangıç yerinden, altta ise ayağın başladığı yerden kırık olarak ele geçmiştir. Gövdenin en geniş olduğu kısım omuzun hemen altında yer almaktadır.

Referans: Chidiroglou 2015: 201, Abb. 2/üst sira soldan 1; Dündar 2008: 22, 121, Lev. 14. U121; Rotroff 2006: Pl. 54/487-89; Guz-Zilberstein 1995: 376, Fig. 6.27/8; Hayes 1991: Pl. XIV/11,12, 17; Vessberg-Westholm 1956: Fig. 24/28; Dotterweich 1999: Taf. 3 Kat. Nr. 1; Lafl1 2003: Taf. 55/e; Körsulu 2011: 86, Res. 21-21a.

Tarih: MÖ 2. yüzyıl sonları.

Katalog No: 10 (Lev. 2/10) Envanter No: FCK12.K16.01.32

Alan/Açma/Derinlik: K16 Açması/KD sektör/f-4 Plankare/Tabaka/216.15

Ölçüler: Taban Ç: $3.6 \mathrm{~cm}$ Korunan Y: $6.6 \mathrm{~cm}$ CK: $0.3 \mathrm{~cm}$

Hamur Rengi: 7.5 YR 6/6 (Reddish Yellow) Yüzey Rengi: 10 YR 6/3 (Pale Brown) Astar: -

Hamur Tanımı: İnce nitelikli yumuşak bir hamur dokusuna sahip olup, çok az çok ince kum ve mika katkılıdır.

Form Tanımı: Küresel gövdeli bir unguentariuma ait ağız ve gövde parçası. Dışa açılan konik, alçak halka kaidelidir. Boyun kısmı eksik olmakla birlikte, paralel örnekler üzerinden uzun silindirik dar bir boyna sahip olduğu düşünülmektedir. Küçük bir parça halinde korunmuş ağız kısmı üzerinden, dışa çekik ağız kenarına sahip olduğu görülmektedir.

Referans: Demargne 1958: Lev. XV, no. 716; Le Roy 2001-2002: 259, Fig. 16; İşkanÇevik 1995: Lev. 6, h, Lev. 7, h; Dündar 2008: 136, Lev. 24. U191, Özdilek 2016: 247, Kat. No. U7-fig. 8; Laflı 2003: Taf. 254/d.

Tarih: Roma Erken İmparatorluk MS 1. yüzyıl.

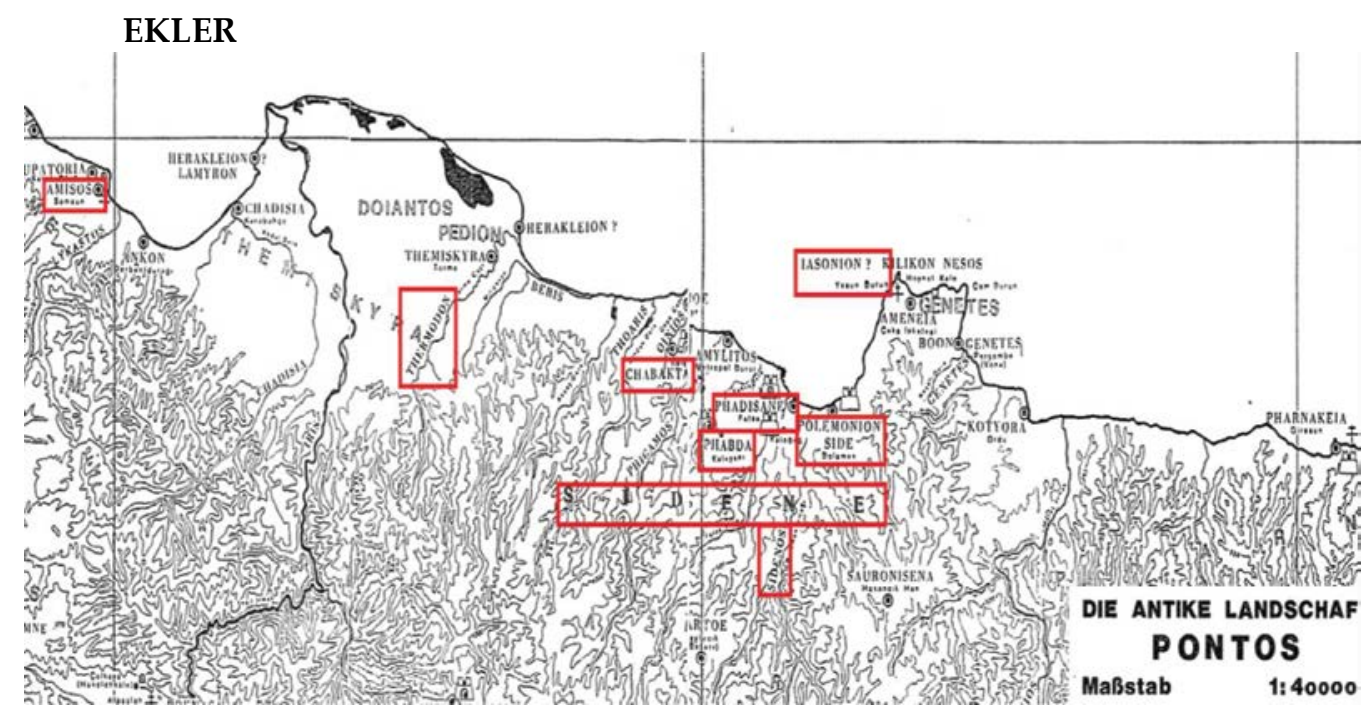

Resim 1: Antik Dönem'de Phabda-Phadisane'nin konumu 


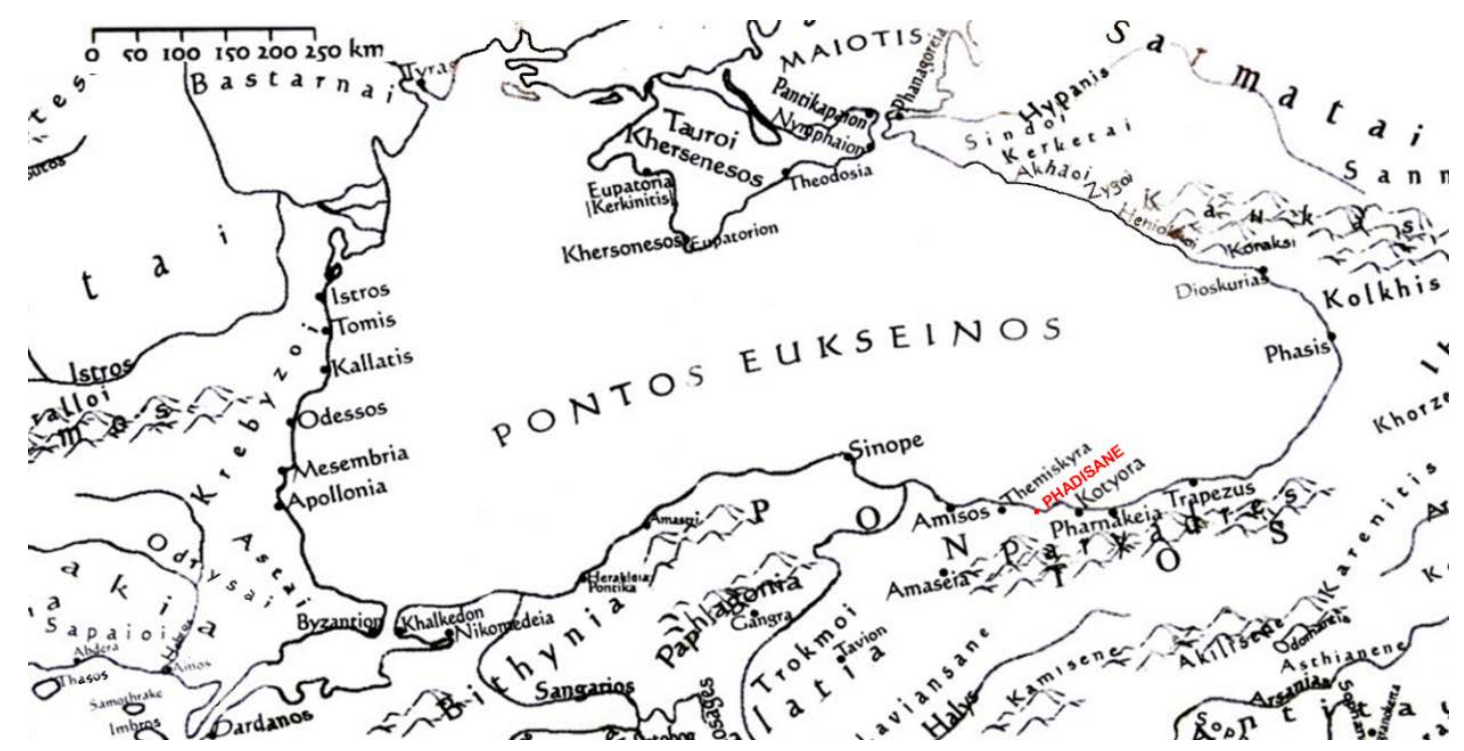

Resim 2: Antik Dönem'de Pontus Havzası

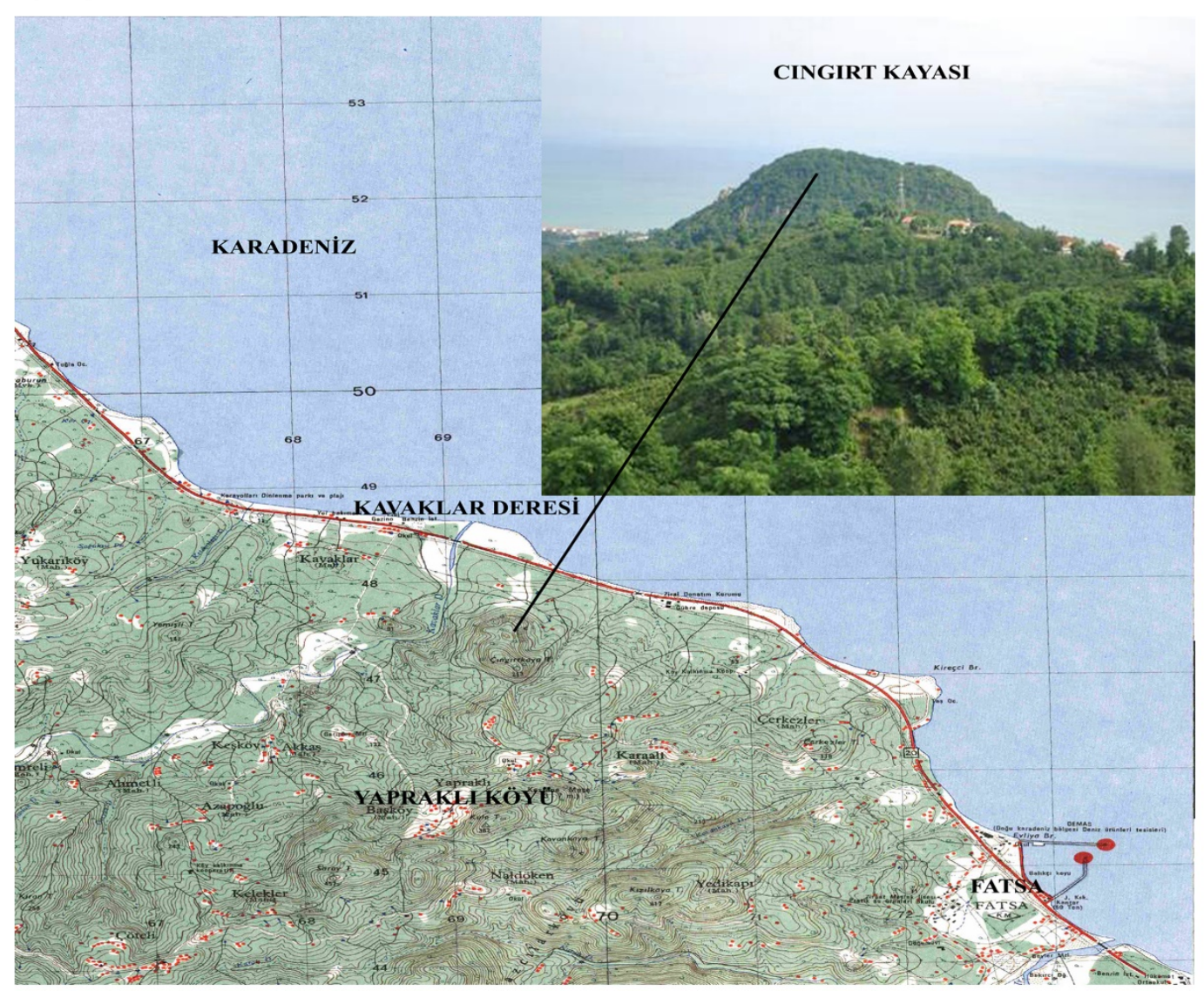

Resim 3: Cıngırt Kayası Coğrafi Konumu 

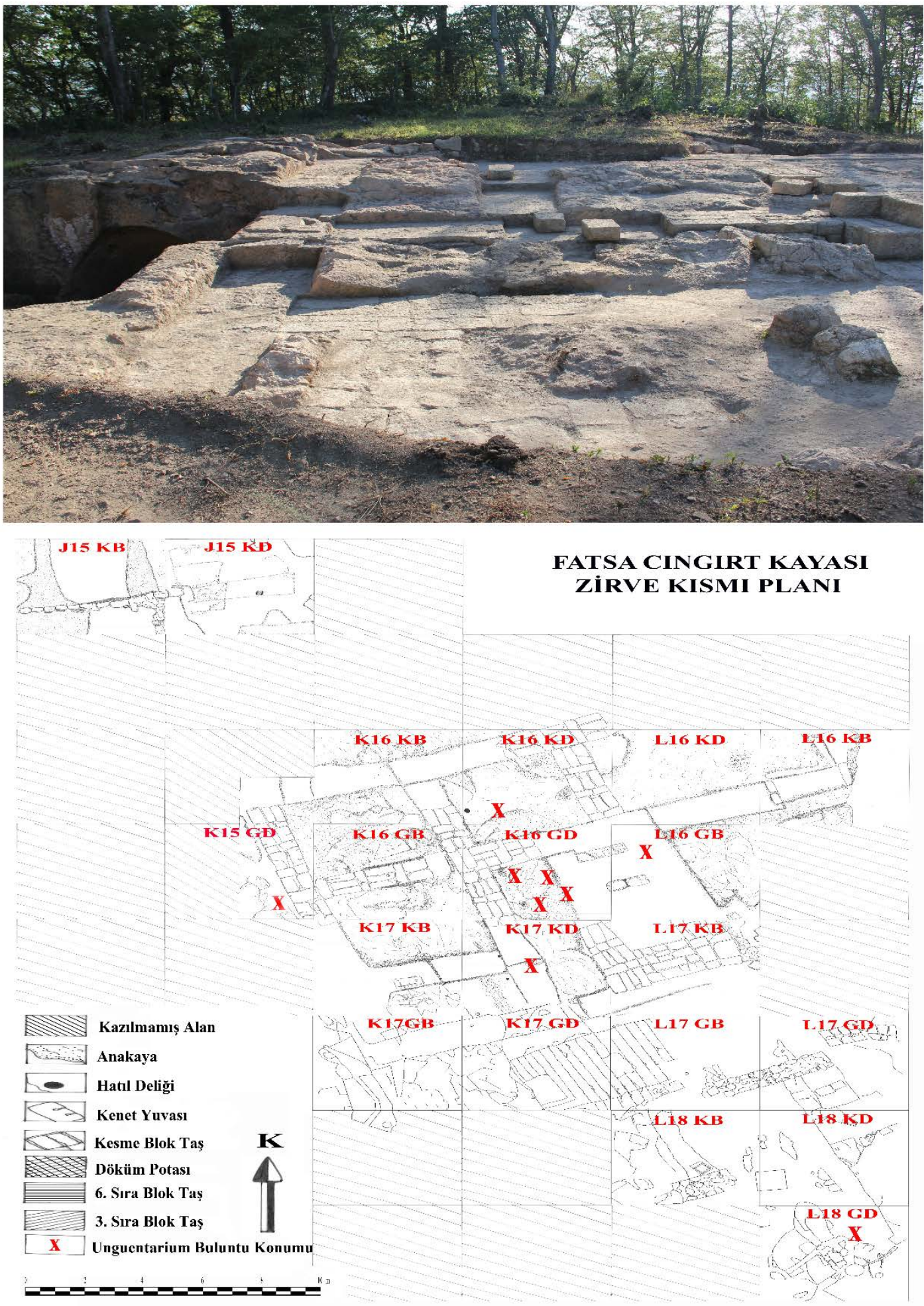

Resim 4: Cıngırt Kayası Zirve Kısmı Planı ve Unguentariumların Arazi Üzerindeki Dağılımı. 


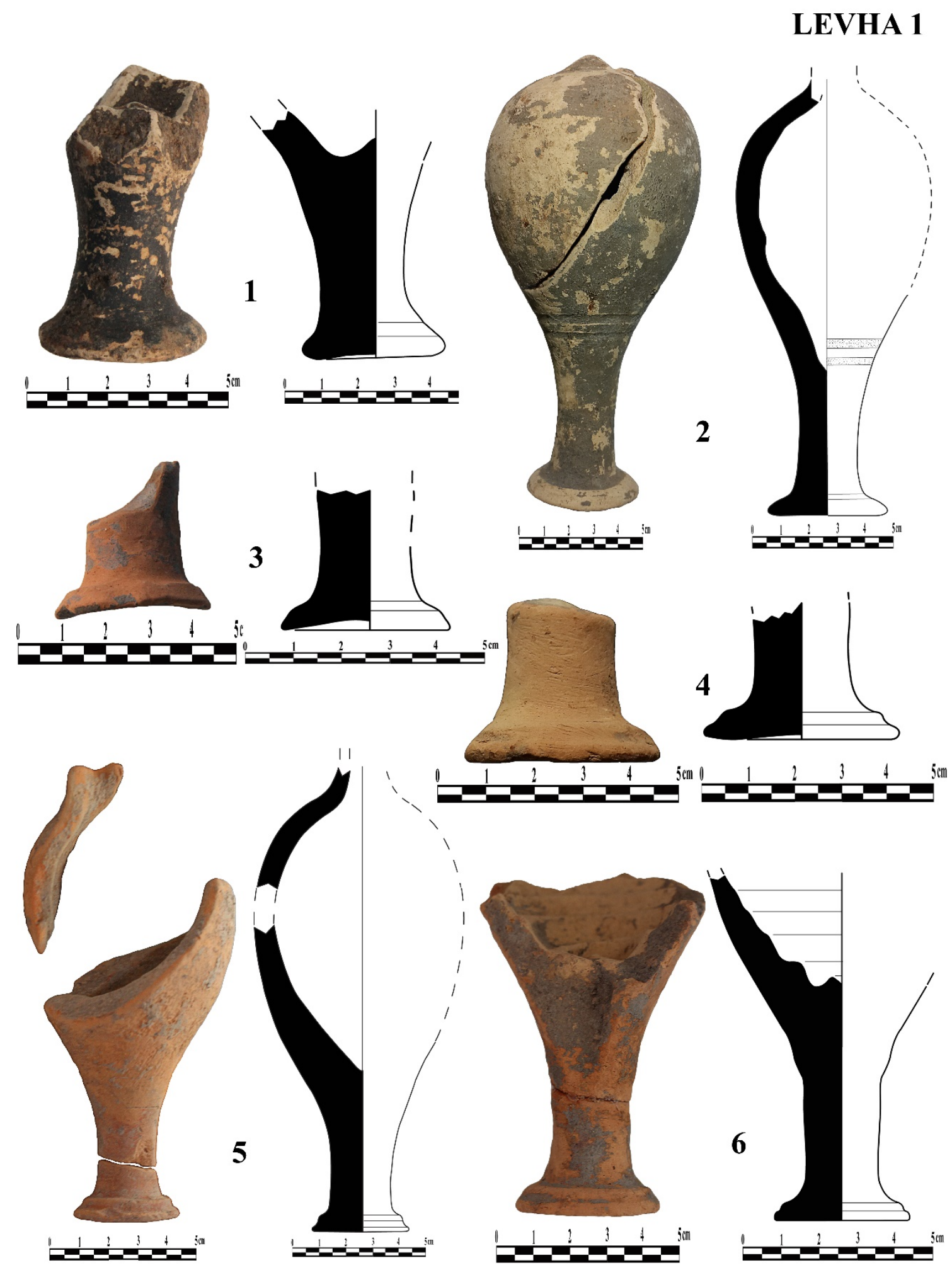

Levha 1: Cingırt Kayası Unguentariumları

SEFAD, 2018 (39): 267-292 

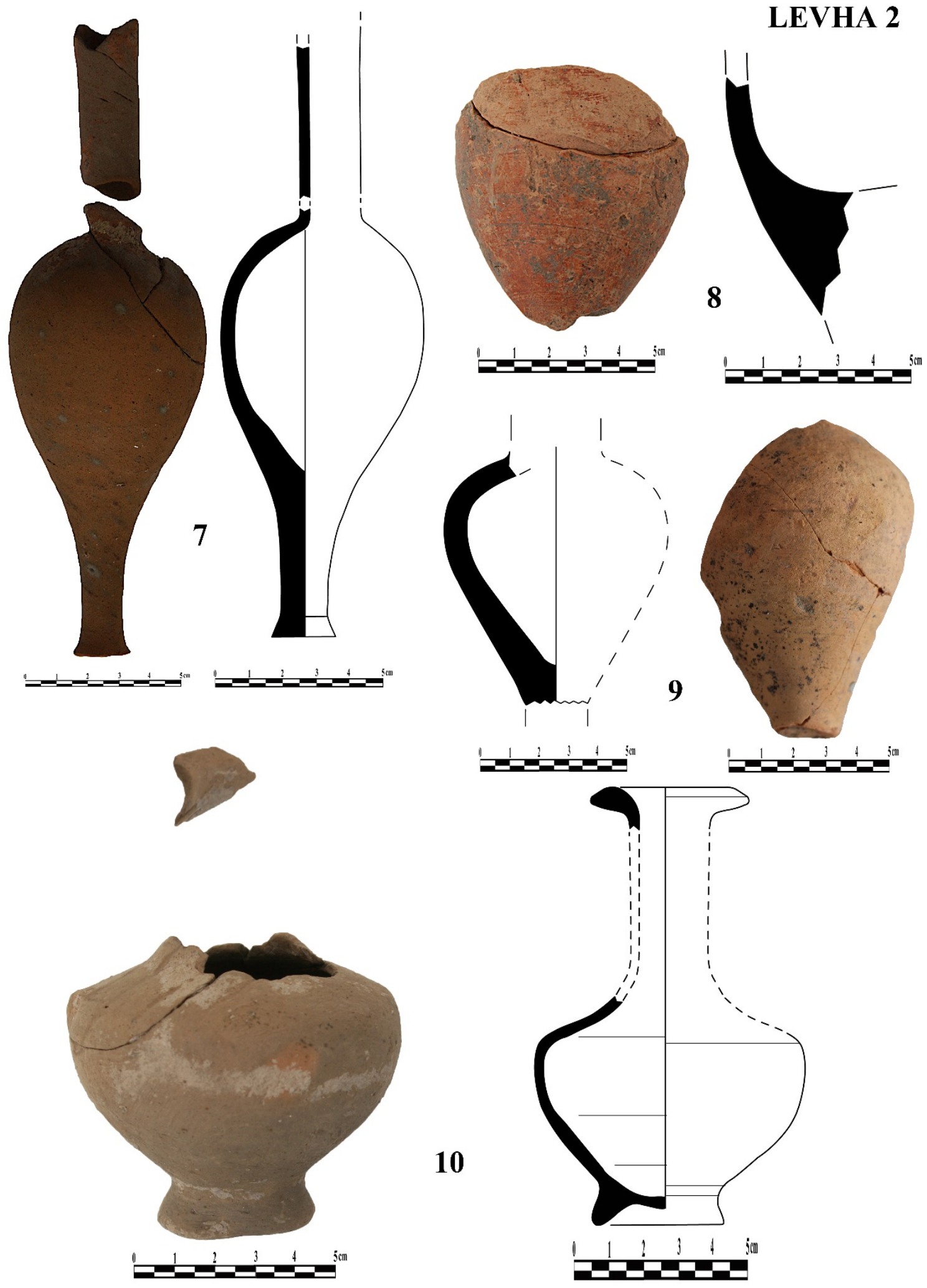

Levha 2: Cingırt Kayası Unguentariumları 